\title{
USDA
}

United States

Department of

Agriculture

Animal and

Plant Health

Inspection

Service

Miscellaneous

Publication No. 1601

Issued December 2008

\section{Center for Plant Health Science and Technology Accomplishments, 2007}

Issued December 2008 


\section{Center for Plant Health Science and Technology}

\section{Mission}

The Center for Plant Health Science and Technology (CPHST) supports the Animal and Plant Health Inspection Service's (APHIS) Plant Protection and Quarantine (PPQ) program's regulatory decisions and operations through methods development, scientific investigation, analysis, and technology.

\section{Strategic Goals}

Enhance PPQ's Efforts in Pest Detection and Management

Provide Timely Scientific and Technical Support Required for Emergency Response and Management

Enhance CPHST Support for APHIS Trade-Related Plant Health Issues

Provide Current Relevant Scientific and Technical Information To PPQ Decisionmakers

Enhance PPQ's Capacity To Anticipate and Respond To Emerging Scientific, Technical, and Regulatory Issues Through Partnerships

The U.S. Department of Agriculture (USDA) prohibits discrimination in all its programs and activities on the basis of race, color, national origin, age, disability, and where applicable, sex, marital status, familial status, parental status, religion, sexual orientation, genetic information, political beliefs, reprisal, or because all or part of an individual's income is derived from any public assistance program. (Not all prohibited bases apply to all programs.) Persons with disabilities who require alternative means for communication of program information (Braille, large print, audiotape, etc.) should contact USDA's TARGET Center at (202) 720-2600 (voice and TDD). To file a complaint of discrimination, write to USDA, Director, Office of Civil Rights, 1400 Independence Avenue, S.W., Washington, D.C. 20250-9410, or call (800) 795-3272 (voice) or (202) 720-6382 (TDD). USDA is an equal opportunity provider and employer. 



\section{Letter From the Director}

This past year's hard work and significant changes have enabled CPHST — a division of the U.S. Department of Agriculture (USDA), APHIS Plant Protection and Quarantine (PPQ) program-to be an organization more capable and better aligned to support and focus on PPQ's scientific needs. In 2007, we developed the first PPQ strategic plan for CPHST. The plan shows where CPHST is going over the next 5 years, how it is going to get there, and how we will know if it got there or not. Moreover, our plan identifies critical elements of PPQ's overall strategic plan that must be supported by the science and technology services CPHST provides. The strategic plan was followed by an operational plan, which guarantees that the strategic plan is a living and breathing document. The operational plan identifies the responsibilities and resources needed to accomplish priorities in this fiscal year and measures our progress.

CPHST identifies the pathways by which invasive plant pests and weeds can be introduced into the United States. We develop, adapt, and support technology to detect, identify, and mitigate the impact of invasive organisms. CPHST helps to ensure that the methods, protocols, and equipment used by PPQ field personnel are effective and efficient.

All the work of CPHST is identified under one of the five program areas: Agricultural Quarantine Inspection and Port Technology, Molecular Diagnostics and Biotechnology, Response and Recovery Systems Technology, Risk and Pathway Analysis, and Survey Detection and Identification. CPHST is comprised of approximately 250 employees in 7 labs and 2 units in the United States, Colombia, and Guatemala. CPHST scientists are leaders in various fields, including risk assessment, survey and detection, geographic information systems (GIS), molecular diagnostics, biocontrol techniques, methods and treatment, and mass rearing of insects.

We actively focus on maximizing our unique skills to deliver and maintain scientific excellence to ensure that PPQ's international and domestic programs have the best scientific information and current technology. To achieve our goals, we work on project development in cooperation with industry, academic institutions, and other State and Federal agencies. 
The following list outlines some of CPHST's efforts in 2007.

Responding to Emergencies-CPHST sponsored several technical working groups (e.g., light brown apple moth, plum pox virus, potato cyst nematode, and citrus greening) to provide sciencebased recommendations when new research findings or changes in pest situations occurred. CPHST also supported these efforts with pest risk assessments, survey and detection techniques, effective treatment options, identification of research needs, and eradication and control recommendations.

Developing and Supporting Technology for Treatments-CPHST continued development of a treatment remote-monitoring system that collects and reports data from quarantine treatments performed at remote locations or in real time during transit.

Increasing Diagnostic Capacity-CPHST developed a network of associated labs called the National Plant Protection Laboratory Accreditation Program (NPPLAP) to increase the capacity of PPQ to meet potential emergency diagnostic needs using standardized methods.

Supporting Trade-CPHST provided PPQ with risk assessments for pests, commodities, and pathways to protect imports and exports from pest threats. CPHST doubled the number of commodity pest risk assessments delivered to PPQ in 2007.

In 2008, we will continue to improve our efforts to mitigate and respond to the heightened threat of accidental and intentional invasive pest and pathogen introductions in the United States. We will develop new approaches to provide our stakeholders with accurate and scientifically sound data and tools to make science-based regulatory and operational decisions.

We are issuing this annual report to provide an informative overview of CPHST's accomplishments and projects in 2007. Our target audience is stakeholders in the private and public sector, the public, and our own CPHST staff.

Philip Berger, Ph.D., Director

Center for Plant Health Science and Technology

USDA, APHIS, PPQ, Raleigh, NC 


\section{Contents}

\section{National Science Programs}

Agricultural Quarantine Inspection and Port Technology ...................................................................... 1

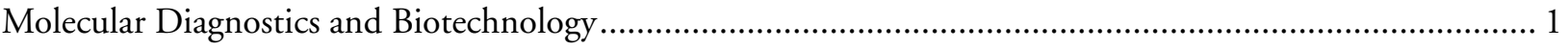

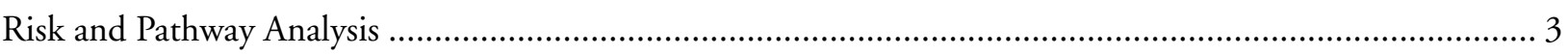

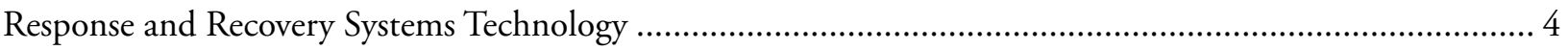

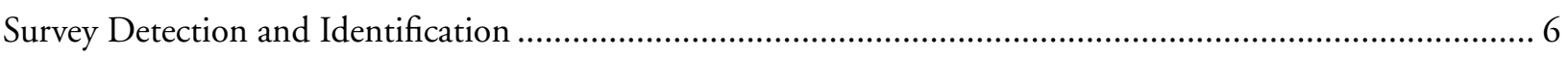

\section{Laboratories and Units}

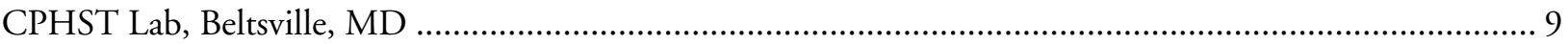

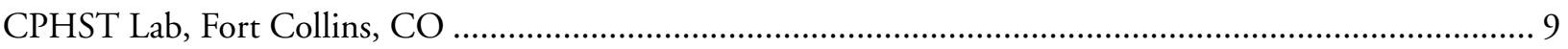

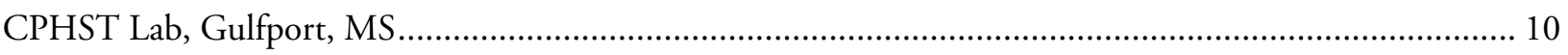

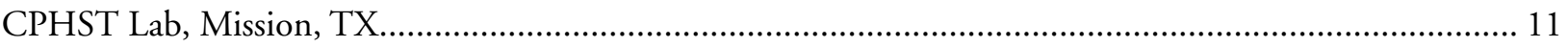

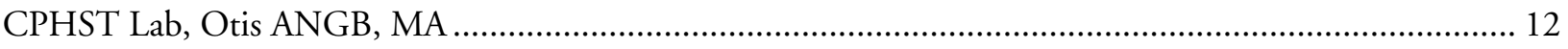

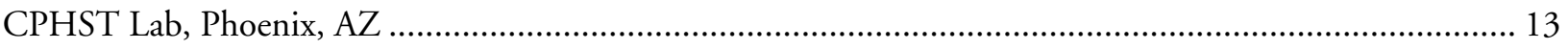

CPHST Plant Epidemiology and Risk Analysis Laboratory …........................................................... 14

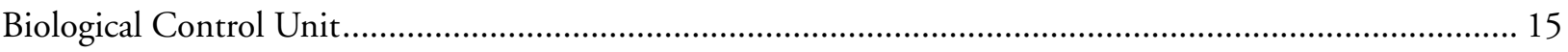

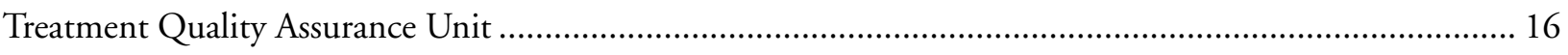

\section{Projects}

Development and Validation of Potato Cyst Nematode (PCN) Detection Protocols ................................. 19

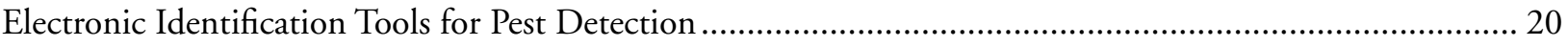

Biological Control of Imported Fire Ants (IFAs) Using Phorid Flies:

Cooperative Rearing and Release Project 
Chilli Thrips (Scirtothrips dorsalis Hood), a New Invasive Pest

in the United States.

Development of Survey Tools for the Emerald Ash Borer .......

Phytosanitary Risks Associated With Armored Scales in U.S.-Bound Commercial

Shipments of Fruit for Consumption

Development of Fungal Pathogens as Control Agents for Rangeland

Grasshoppers and Mormon Crickets

Classical Biological Control of the Emerald Ash Borer

Development and Implementation of Organizational and Technical

Infrastructure To Support Use of Irradiation as a Phytosanitary Treatment

\section{International Collaboration}

Safeguarding Our Borders

\section{List of Funded Projects for Fiscal Year 2007}

Beltsville Lab

Fort Collins Lab

Gulfport Lab

Mission Lab

Otis Lab

Phoenix Lab

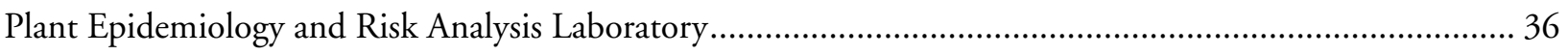

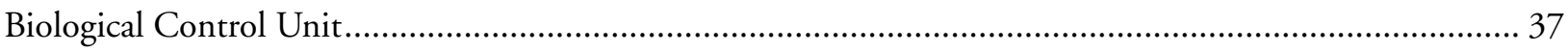

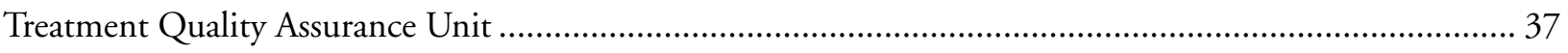

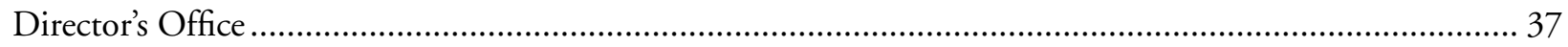





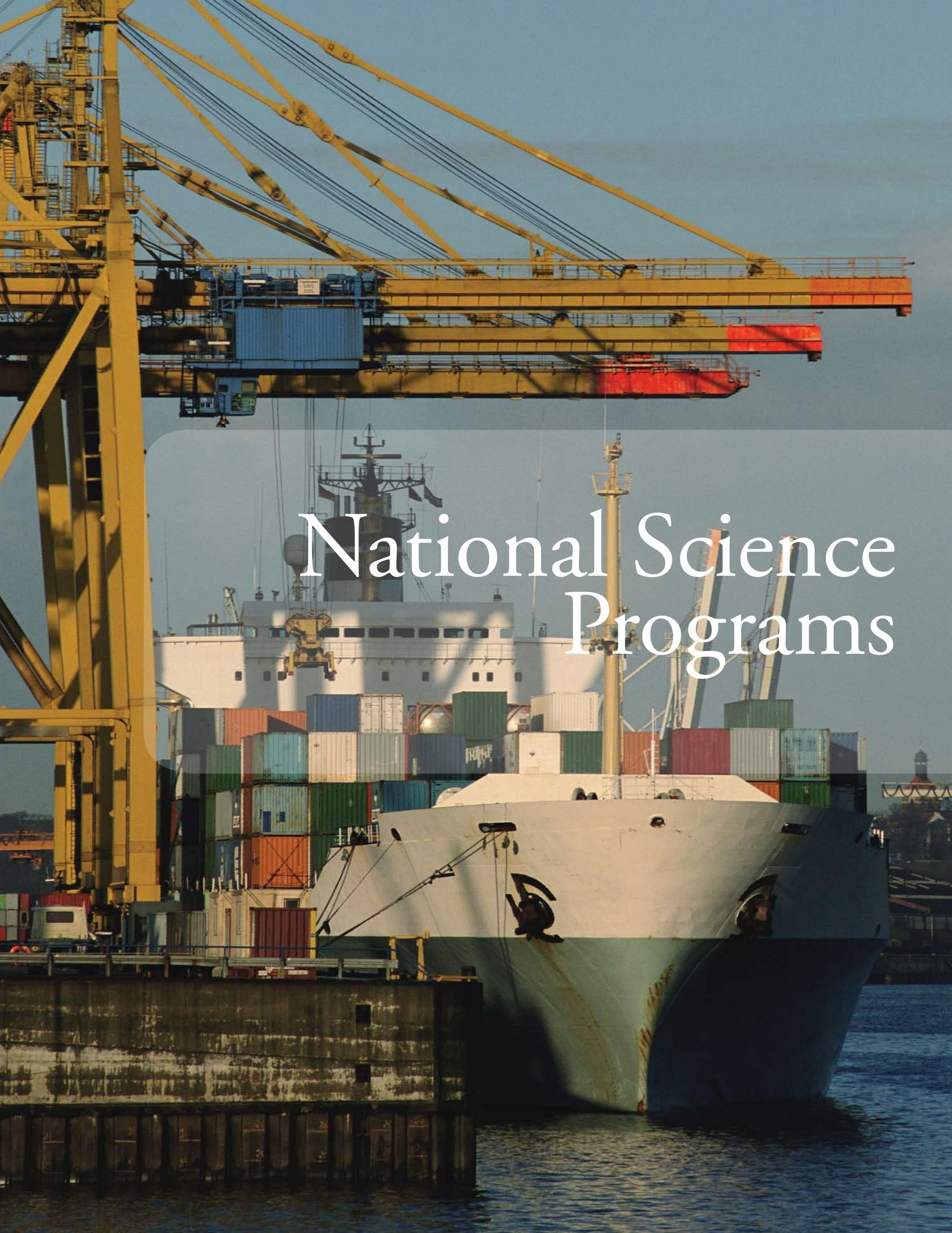




\section{Agricultural Quarantine Inspection and Port Technology}

\section{Who We Are}

As agricultural imports increase, so does the threat of pest introductions. Quarantine inspections and mitigating treatments represent the tools used in the last line of defense against exotic invaders and, therefore, serve both to guarantee the safety of our agricultural imports and to promote international trade. The mission of the Agricultural Quarantine Inspection and Port Technology (AQIPT) program is to provide the scientific basis upon which these agricultural import inspections and treatment technologies are based.

\section{What We Do}

The basic responsibilities of the AQIPT program can be grouped into the following categories:

- Development of treatment manuals to support the work of the U.S. Department of Homeland Security (DHS) at U.S. ports of entry;

- Certification of vessels and containers for transporting commodities;

- Development of alternatives to the use of methyl bromide;

- Maintenance of a database for monitoring the use of fumigants;

- Certification of international commodity treatment facilities in preclearance programs; and,

- Development of detection technologies for port deployment, such as chemical sensors, acoustical detectors, and agricultural $x$-ray technology.

Within this framework, the AQIPT program supports numerous activities. Ongoing research is documenting the efficacy of both chemical and nonchemical treatment options, including heat, metabolic stress disinfection and disinfestation (MSDD), and fumigants (e.g., sulfuryl fluoride, methyl iodide, and phosphine). These treatments are used to disinfest commodities ranging from firewood, logs, and solid wood packing material to fresh produce. In the area of detection technologies, progress will continue on the development of an electronic nose and trace element analysis, both of which will provide enhanced detection of invasive species and contraband materials. The Treatment Quality Assurance Unit is developing a treatment remote-monitoring system capable of collecting, analyzing, and reporting data from quarantine treatments performed at remote locations or in real time during transit. This technology, which is one component of a commodity treatment information management system, will increase the efficiency of data analysis, facilitate commodity tracking, and expedite the release of cargo. The AQIPT program continues the analysis of cooperator-produced transgenic strains of Mediterranean fruit fly (Medfly, Ceritatis capitata), which will allow organisms carrying the genetic constructs for sex-specific lethality, sterility, and fluorescence to be used in the sterile insect technique (SIT) program. This technology will thus serve to minimize operational costs and enhance identification of sterile flies. The AQIPT program has also worked in collaboration with other members of the International Plant Protection Convention (IPPC) to produce an international standard addressing phytosanitary treatments for regulated pests and has submitted various proposals outlining irradiation treatments to be considered for inclusion in an "international treatment manual.”

\section{Where We Are Going}

In the future, agricultural quarantine inspection (AQI) activities will focus on the continued development and implementation of technologies in four primary areas: alternatives to methyl bromide, new pest-detection tools, electronic tracking and information management, and improved fruit-fly management practices.

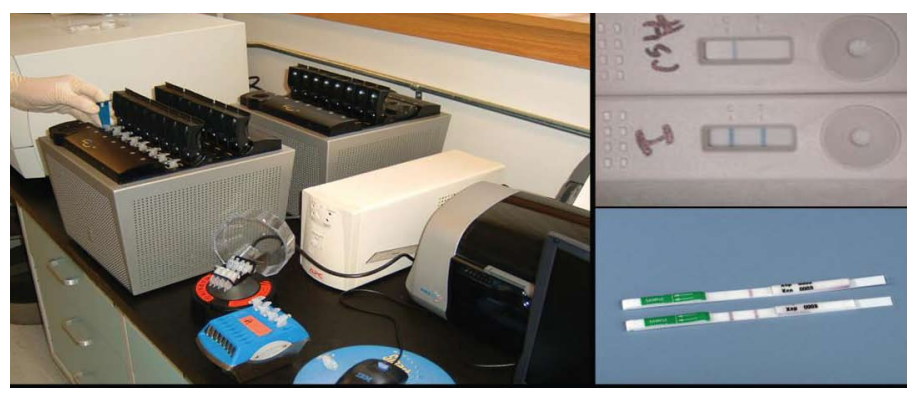

Figure 1-Equipment for performing serological tests using polymerase chain reaction (PCR) technology.

\section{Molecular Diagnostics and Biotechnology}

\section{Who We Are}

The Molecular Diagnostics and Biotechnology (MDB) program's mission is to provide scientific support to APHIS-PPQ for characterization of pest organisms requiring molecular diagnostics and to support the development of genetically modified (GM) organisms for use in pest management programs. The MDB program identifies, develops, and adapts appro- 
priate technologies (fig. 1) for molecular-based detection and identification of plant pests and pathogens and validates molecular assays for use by the regulatory community. Additionally, the MDB program supports GM insect development for the control of crop pests and strategy formulation for the regulation and eventual deployment of GM insects.

Our vision is to identify and employ effective technologies to ensure that PPQ delivers successful programs. In order for this to occur, our molecular assays must be highly reproducible and robust. Program activities include:

- Evaluation and development of new technologies for molecular diagnosis of exotic pests and pathogens;

- Validation of molecular diagnostics;

- Development and deployment of proficiency tests for external laboratories;

- Training collaborators on the use of specific molecular diagnostics;

- Providing quality assurance for accepted, validated molecular diagnostics; and,

- Providing support in the environmental assessment of transgenic insects for use in regulatory programs.

\section{What We Do}

The MDB program provides science-based support for several PPQ programmatic efforts, such as the citrus health response and Phytophthora ramorum (sudden oak death) emergency programs. MDB also supports improved responses to emergent pest introductions into the United States, including the recent potato cyst nematode (PCN, Globodera pallida) and plum pox virus (PPV) finds. In 2007, the MDB program sponsored several technical working groups to provide science-based recommendations when new research findings or changes in the pest situations occurred.

The MDB program has developed a network of associated labs called the National Plant Protection Laboratory Accreditation Program (NPPLAP) to increase the capacity of APHIS-PPQ to meet potential emergency diagnostic needs using standardized methods. This new program focuses on diagnostic protocol standardization and lab proficiency testing for molecular diagnosis of high-consequence pests. Currently, administration of diagnostic capacity for the citrus greening [huanglongbing] pathogen (Candidatus liberibacter asiaticus) and Phytophthora ramorum occurs under NPPLAP through the MDB program and the CPHST Beltsville [MD] Lab.
The primary strategy presently employed by APHIS for the control of three pest insects is the SIT. The MDB staff provides support and documentation for the development and environmental assessment of transgenic pink bollworm and transgenic Mexican fruit fly (Mexfly, Anastrepha ludens) and Medfly, which occurs at the CPHST Phoenix [AZ] Lab and the CPHST Mission [TX] Lab, respectively. The MDB program provides additional support for the method development of molecular diagnostics for insect pests that may be difficult to identify using standard approaches.

The MDB supports the Integrated Consortium of Laboratory Networks (ICLN). Signatories, who include 10 Federal agencies or departments and represent all U.S. laboratory networks, have agreed to work cooperatively to optimize national laboratory preparedness by improving coordination of laboratory response to incidents. ICLN members promote common standards of performance across all lab response assets to ensure that data supporting homeland security decisions are of the best quality and are defensible. The ICLN assesses gaps in coverage across multiple sample types, potential victim groups (human, animal, and plant), and all response phases and works to rationalize and enhance relevant interagency budgets. The ICLN is a U.S. homeland security infrastructure with a coordinated and operational system of laboratory networks that provides timely, high-quality, and interpretable results for early detection and effective consequence management of acts of terrorism and other events requiring an integrated laboratory response. The MDB staff belongs to ICLN Network Coordinating Group, as well as a variety of subgroups addressing training, proficiency testing, laboratory accreditation and quality assurance, methods development, scenario development, and information technology.

The MDB program continues to learn about and assess emergent technologies that may be useful for PPQ programs by increasing capacity or by streamlining current efforts. In addition, the MDB program also provides support to decisionmakers on the impact of new technologies on the safeguarding of U.S. agriculture from accidental or deliberate introductions of high-consequence pests into the United States. 


\section{Where We Are Going}

The use of molecular methods by a variety of programs is rapidly increasing to meet the challenges faced by PPQ and will probably increase further as our society faces new challenges. As the primary support for molecular methods within PPQ, MDB personnel scan emergent molecular technologies for potential adoption by PPQ programs. We are also charged with informing the developers of these new technologies about the unique needs of PPQ, so that future technologies are developed with these needs addressed.

Another focus of future activity will be to expand upon efforts to engage and coordinate the molecular diagnostic capacity outside of the PPQ system for use by PPQ programs. The continued development of accreditation and certification programs will increase the quality of procedures and reporting expectations at participating laboratories systemwide. These programs are designed to reduce risk of misdiagnosis and produce standards that are at the forefront of diagnostic capacity and adopted internationally as the standards for molecular protocols and diagnosis.

\section{Risk and Pathway Analysis}

\section{Who We Are}

The Risk and Pathway Analysis (RPA) program focuses on collecting and interpreting scientific evidence and technical information regarding plant pest risks. RPA products help PPQ design risk-based policies and regulations for import, export, and domestic programs. The work of the staff is important for identifying and assessing new pest threats (fig. 2), providing scientific support to regulatory updates and revisions, and helping prioritize resources to maximize protection capabilities.

RPA is supported primarily by the Plant Epidemiology and Risk Analysis Laboratory (PERAL) located in Raleigh, NC, with satellite staff in Hawaii and Bogotá, Colombia. PERAL collaborates with other CPHST laboratories, other groups in PPQ and USDA (e.g., the Agricultural Research Service [ARS]), academia, foreign counterparts, and stakeholders in developing scientific analyses that are essential for the formulation, implementation, and modification of risk-based phytosanitary policies and procedures.

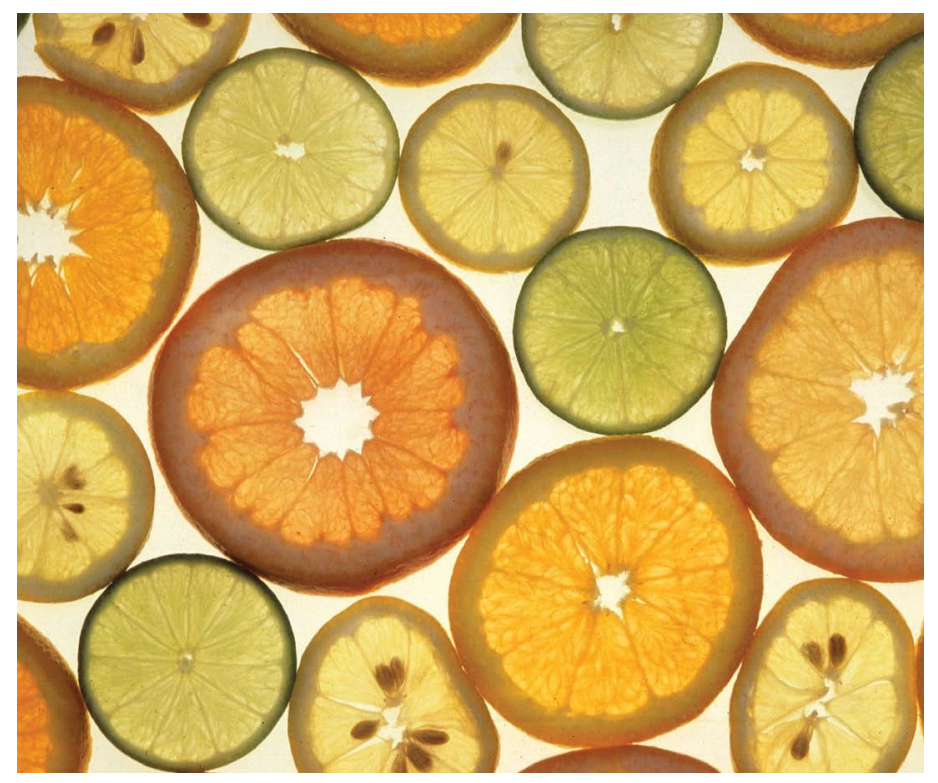

Figure 2-Citrus imported from countries where fruit flies are indigenous could bring these non-native pests into the United States.

\section{What We Do}

The foundation of RPA's analytical capacity is its diverse, high-caliber scientific staff, composed of entomologists, plant pathologists, botanists, ecologists, economists, and other specialists combined with an extensive, unique, and ever-growing collection of information on plant pests. RPA uses state-ofthe-art tools and methodologies for pest risk assessment, including sophisticated spatial technology systems that integrate weather, pest distribution, and other databases to analyze pest dynamics; identify agro-environmental pests of greatest concern; and identify potential pathways for the introduction of harmful exotic pests and predict their spread.

RPA program capabilities have expanded rapidly over the past few years to become a central function for PPQ and an international benchmark for pest risk analysis (PRA). PERAL established itself as a global leader in both productivity and quality management. PERAL is currently the only International Standards Organization (ISO)-certified plant-health risk-analysis unit in the world. The group contributes significantly to the promotion of international dialogue and increased capacity for science-based management of phytosanitary issues through its Risk Analysis Mentoring Program (RAMP) for visiting scientists. Likewise, PERAL promotes regional and international harmonization of plant health regulations by participating in the North American 
Plant Protection Organization (NAPPO) and the International Plant Protection Convention (IPPC). PERAL provides technical direction to the new CPHST Colombia group (a subgroup of the Center for Phytosanitary Excellence located in Colombia). The group is tasked with a broad range of CPHST work, including risk analysis, data gathering, and treatment research.

\section{Where We Are Going}

Future plans include promoting the continued evolution of risk analysis tools and methodologies while also increasing the transparency and efficiency of processes. Increasing emphasis is expected to be given to risk assessments for pest plants (noxious weeds) and propagative material.

\section{Response and Recovery Systems Technology}

\section{Who We Are}

The mission of the Response and Recovery Systems Technology (RRST) program is to provide timely scientific support to regulatory program managers and decisionmakers when recognized, high-consequence plant pests have been detected in the United States. The program emphasizes preventive measures that minimize the chances such introductions will occur and develops rapid response and recovery technologies geared toward eradication or containment of newly detected pests.

\section{What We Do}

RRST supports a wide range of plant health programs, which are described in more detail below. As with all APHIS PPQ work, these programs use integrated pest management strategies, phytosanitary measures, and technologies to combat exotic diseases and pests while minimizing adverse affects on the environment, producers, and consumers.

Citrus Health Response Program-The Citrus Health Response Program (CHRP) was formed in response to the establishment of citrus canker and citrus greening (also called huanglongbing [HLB]) in Florida and the potential for other pests and pathogens to enter U.S. citrus-production areas. CHRP is based on citrus disease management using harmonized production standards across all citrus-producing States. A technical working group (TWG) convened in 2007 to review, define, and identify conditions under which nursery stock intended for shipment to non-citrus-producing States can be produced and shipped with no (or very low) risk of movement of citrus canker, HLB, or the Asian citrus psyllid (the insect vector of HLB).
Light Brown Apple Moth-The light brown apple moth (LBAM), Epiphyas postvittana, was detected and confirmed in Alameda County, CA, in March 2007 (fig. 3). If left uncontrolled, LBAM could cause significant damage to many different crops, including stone fruits, pome fruits, grapes, and citrus. A Technical Working Group comprised of scientists from the United States, Australia, and New Zealand was formed to make recommendations for potential eradication or control of the pest, develop management recommendations, assess research needs, and provide ongoing scientific input to program operations.

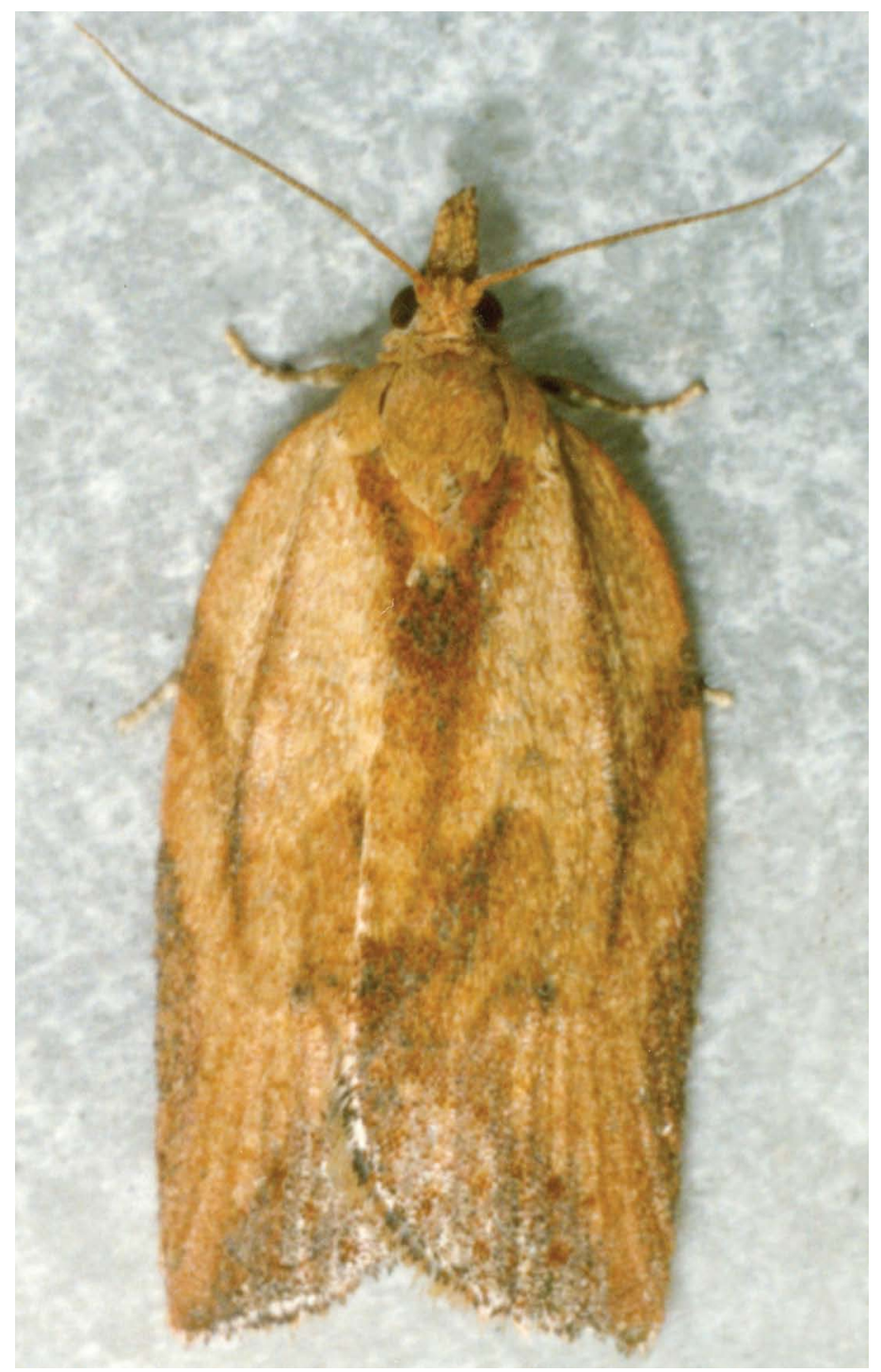

Figure 3-Single light brown apple moth (Epiphyas postivittana). 
Panicle Rice Mite-Since its confirmed detection in July 2007, panicle rice mite (PRM), Steneotarsonemus spinki, has been found at rice research facilities (fields and greenhouses) in several U.S. States and Puerto Rico, as well as in growers' fields in one State. A TWG of mite and rice experts was assembled to develop management recommendations for this serious rice pest and to advise on the feasibility of eradication efforts.

Pineapple Heart Rot-In March 2007, a TWG convened to gather information and provide technical guidance to State and Federal regulatory officials on the status of pineapple heart rot disease in Hawaii. The TWG reviewed information on the different aspects of the disease's distribution in pineapple fields; the biology, survival, and dispersal mechanisms of the pathogen Erwinia chrysanthemi; the methodology for detection and rapid diagnosis of the pathogen; and the evaluation of mitigation measures needed to control the spread of this disease.

Fruit Fly Introductions-The Moscamed Program in Guatemala irradiates billions of Medflies a year for prevention and eradication activities. In an effort to improve cost efficiency and effectiveness of sterile-Medfly releases, the development of a genetically sterile strain is being investigated as a possible alternative to irradiation. A team of scientists was formed to guide and evaluate these activities. The RRST program also provides general scientific support to eradication efforts for recent Medfly detections in California and Mexfly finds in Texas.

Red Palm Mite-Red palm mite (RPM), Raoiella indicaa pest of coconuts and ornamental palms in Asia and Africa-arrived in the Caribbean in 2004. By 2007, the pest had spread to at least 11 islands, including Puerto Rico and the U.S. Virgin Islands, and late in 2007, it was found in Florida. RPM is already having serious impacts on the coconut and banana industries in the Caribbean and is expected to cause economic damage to tropical and subtropical agriculture wherever palms are grown in the Western Hemisphere. CPHST chairs the TWG, which developed management recommendations, supports continued surveillance activities, and oversees the assessment of biological control (BC) options for this important pest.
Plum Pox Virus-Several plum pox virus (PPV) science panels were convened in 2006 and 2007 in response to detections of PPV in New York, Michigan, and Canada. One of the tasks of the panel was to review the current eradication program in Pennsylvania to analyze the program components that may be applicable to newer finds and situations. Recommendations from the science panel were used to focus and prioritize program components suitable for phytosanitary actions.

Potato Cyst Nematode-In response to a 2006 detection of potato cyst nematode (PCN) in Idaho potato fields, a TWG was convened to discuss the pest's status and to make management recommendations based on current scientific knowledge and expertise. The PCN TWG was charged with providing scientific support to the regulatory program based on timely information as the response and resulting infrastructure developed. The TWG also provided support on issues related to survey and detection of PCN in a national survey for this pest.

Phytophthora ramorum-CPHST provided ongoing scientific support by participating in science panel meetings and recommending modifications to eradication protocols made necessary as new scientific information became available. Rapid incorporation of new scientific developments continues to be a major driver of our response and recovery efforts.

Gladiolus Rust-A TWG meeting was held in 2007 to review information on the biology of the gladiolus rust (GR) pathogen, Uromyces transversalis, evaluate the control recommendations already in practice for this disease, and evaluate progress toward eradication. This meeting focused on Florida's efforts in eradication. An additional TWG meeting in early 2008 included both Florida and California to reevaluate the feasibility of eradication, management options if it is deemed infeasible, and ongoing research needs to support regulatory decisionmaking. 


\section{Where We Are Going}

The RRST program continues to evolve as it seeks to meet the challenges presented by an increasing arrival rate of exotic diseases and pest species. In 2008, RRST will seek to further increase its linkages with national programs managed by PPQ headquarters under Emergency and Domestic Programs, as well as the Western and Eastern Regions. RRST will also focus on using the output from pathway analyses and overseas information-gathering efforts to prepare for future pest threats and to support the development of new management programs.

\section{Survey Detection and Identification}

\section{Who We Are}

The Survey Detection and Identification (SDI) program provides sound science and demonstrated methodologies to PPQ for rapid detection and identification of exotic pests. The SDI program is divided into four cross-functional groups: early detection, identification technology, spatial technology, and biocontrol. SDI supports PPQ programs through ad hoc and long-term projects, committee memberships, and virtual teams. Additional support is gleaned through cooperation with academic institutions, industry, and other government agencies.

The SDI early detection team supports national pest surveillance through the PPQ Cooperative Agricultural Pest Survey (CAPS). SDI provides survey support to CAPS through pest prioritization, commodity-based survey guidelines, trap and lure development, and offshore methods development. In addition, SDI provides support to emergency programs in the form of survey development (fig. 4).

The SDI identification technology team develops Lucid taxonomic tools and provides training in and technical support for Lucid tools and other computer-based identification resources. Additionally, the group has developed an automated system for sorting and identifying insects using digital recognition technology and robots.

The SDI spatial technology team provides support in the fields of geographic information systems (GIS) and remote sensing. Examples include risk maps in support of CAPS and emergency programs and remote sensing to detect the efficacy of weed control efforts.

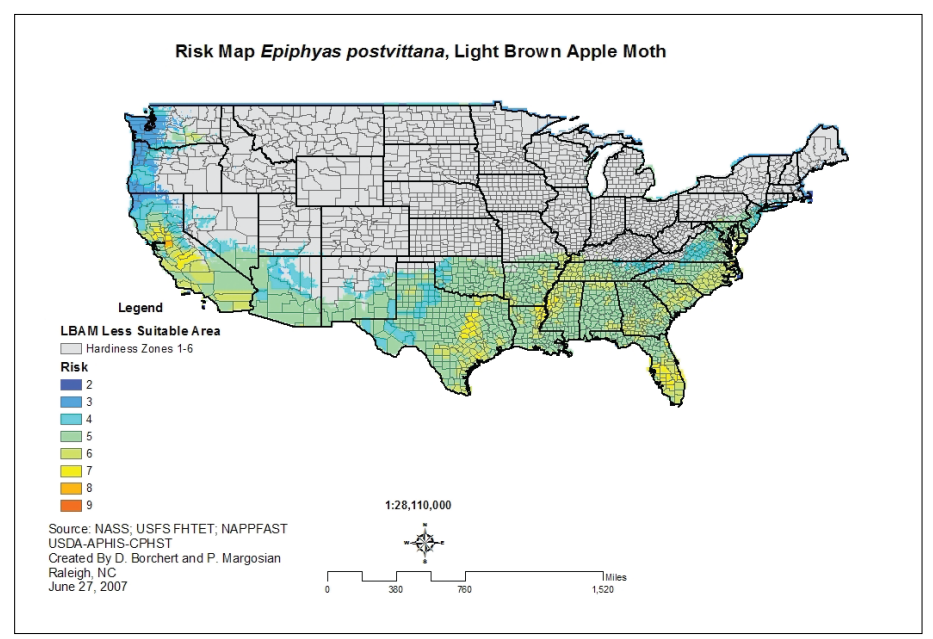

Figure 4-This risk map-developed for the Light Brown Apple Moth National Survey -incorporates host-crop distribution, pest degree-day data, and USDA plant hardiness zones to predict geographic areas at risk for LBAM establishment.

The SDI biocontrol team develops and matures technology to eradicate or manage exotic organisms. The process includes identification of natural enemies and competitors, development of rearing technologies and release techniques, and monitoring of released biocontrol agents.

\section{What We Do}

With a pipeline of more than 40 active projects, SDI develops tools and technologies to protect American plant resources. The SDI program strives to provide leadership in offshore initiatives and outreach to diverse audiences to enlist support for PPQ goals. The SDI staff seeks and identifies new technologies from external groups and adapts them to fit the needs of plant protection initiatives. Collaboration and coordination occurs between the SDI program and CPHST labs to develop efficient traps, pheromones, and survey techniques. SDI is committed to recruit the best scientific talent to ensure the best quality of work and results.

\section{Where We Are Going}

Decisionmakers recognize the urgent need for early detection of plant pests. Tremendous plant resources are vulnerable to pest introductions. Early detection of pests often provides significant long-term savings by reducing pest control costs and increasing the feasibility of eradication. In response, leaders have increased pest detection resources. The SDI program will continue to develop and improve tools and technologies that promote early detection and identification of exotic pests. 



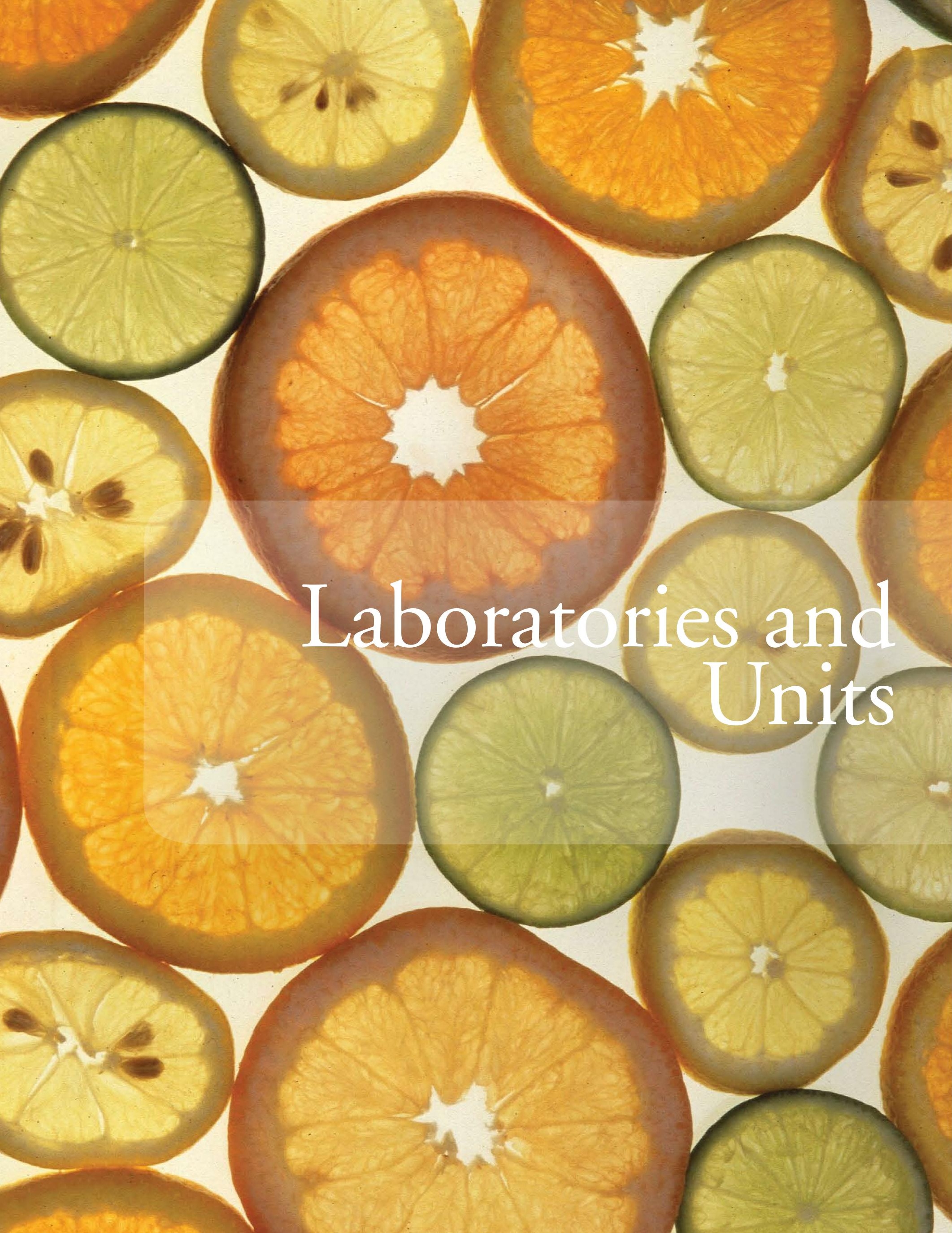




\section{CPHST Lab, Beltsville, MD}

\section{How We Support the Mission}

The Beltsville Lab is responsible for the development, evaluation, and adaptation of advanced biochemical and molecular methods and new technology platforms for the detection of high-consequence plant pathogens, including the APHIS Select Agents. The methods are rigorously validated within this laboratory, and lab personnel also engage external laboratories in multi-lab validations, including international laboratories. The Beltsville Lab interacts with other Federal and international entities and regulatory agencies in working toward standardization protocols to develop and validate diagnostic methods and for quality assurance protocols.

Lab employees transfer and implement validated methods through hands-on laboratory training of scientists within PPQ, State departments of agriculture, and land-grant universities that make up the National Plant Diagnostic Network (NPDN) managed by USDA's Cooperative State Research, Education, and Extension Service (CSREES). The Beltsville Lab supports the CPHST National Plant Pathogen Laboratory Accreditation Program (NPPLAP) through the development and validation of proficiency test (PT) panels and analyst PT performance evaluation. The Beltsville Lab not only deploys cutting-edge diagnostic methods, but also uses these methods for the accurate and rapid diagnosis of high-consequence plant pathogens.

\section{Recent Accomplishments}

- Validated three conventional PCR methods acquired from ARS for the detection of PCN and differentiation of Globodera pallida, G. rostochiensis, and G. tabacum. Developed a simplified nematode extraction method and real-time PCR assays for the specific detection of these three species.

- Validated three real-time PCR methods acquired from the Canadian Food Inspection Agency (CFIA) and one published by the Central Science Laboratory (CSL) in the United Kingdom for detection of Phytophthora ramorum in response to a request by the National Plant Board to find new gene targets for detection. Two are promising.
- Developed a microelectronic DNA chip for the detection of PPV and differentiation of its various strains (a scientific paper is in development).

- Improved the extraction protocol and PCR method for Asian citrus psyllids (ACP) infested with the pathogen that causes citrus greening, Candidatus liberibacter. The method uses a closed extraction system, and the PCR uses a stable psyllid internal control to monitor the DNA extraction quality, increasing confidence in PCR analysis results.

- Delivered the third sudden oak death proficiency test panel and distributed it to 31 analysts representing 18 laboratories. Developed and validated a citrus tissuebased proficiency test panel for citrus greening, the first Select Agent proficiency test panel developed for distribution by NPPLAP.

- Beltsville Lab scientists serve on ICLN subcommittees for Methods Development, Accreditation and Quality Control Proficiency Testing, and Training. Beltsville Lab scientists are contributing members of PPQ Task Forces, participate on working groups to develop recovery plans for the National Plant Disease Recovery System, and serve as subject experts for professional journals and grant review panels for U.S. and international granting agencies.

\section{CPHST Lab, Fort Collins, CO}

\section{How We Support the Mission}

This laboratory develops science-based methods, innovative tools, and state-of-the-art technology to reduce levels of risk associated with new and established weed species (fig. 5) and imported plants for planting and transfers these tools to PPQ and other Federal and State agencies. In addition, the Fort Collins Lab provides science support for pest detection and survey methods under the Cooperative Agricultural Pest Survey (CAPS) program. The laboratory transfers methodologies and tools to field operations, ensuring efficient and effective survey, detection, identification, emergency response, and eradication. This lab is the primary source for new technologies to support rapid, consistent, and accurate identification and nomenclature of pest species through development of 
electronic, matrix-based identification resources. At an offsite station in Albany, CA, staff members develop artificial diets and rearing systems for biocontrol agents. The Fort Collins Lab is APHIS' clearinghouse for the management of invasive plants and plants on the Federal Noxious Weeds list through applications of biocontrol. This lab provides engineering expertise in automated screening of biological materials and detection of alien species posing potential risk to agriculture and natural resources. From the Fort Collins Lab, PPQ operational programs receive spatial technology support to guide them in the application of new geospatial survey and detection methods.

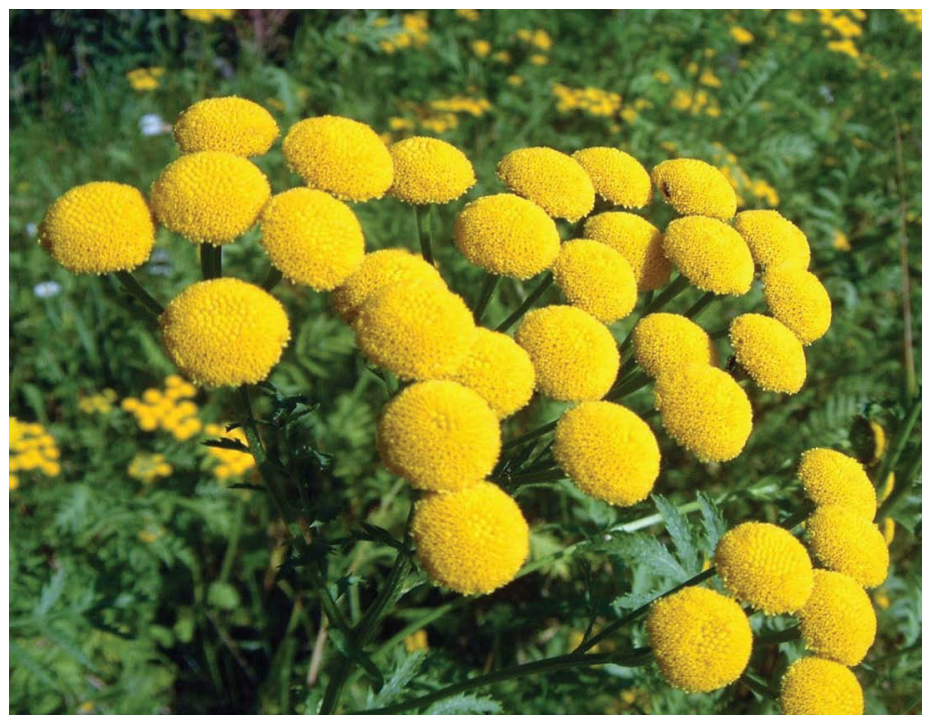

Figure 5-Despite its attractive flowers, common tansy (Tanacetum vulgare) is an invasive weed of concern in several States. (Photo by Michael Shepard, USDA Forest Service.)

\section{Recent Accomplishments}

- Established colonies of LBAMs to develop improved rearing systems in support of research, molecular diagnostics, and biocontrol initiatives.

- Supported the CAPS community by developing riskassessment maps for the top 50 CAPS pests for distribution on the NAPPFAST Web site and completing soybean commodity-based survey guidelines and a grape commodity-based survey.

- Completed analysis of the effects of biocontrol on saltcedar infestations using remote sensing and hyperspectral imaging tools.
- Conducted hands-on training workshops on the use of electronic matrix-based Lucid tools at the Los Angeles, Seattle, John F. Kennedy Airport, and Miami Plant Inspection Stations and at the University of Florida and Florida A\&M University. Published three Internet-based Lucid tools: "Aquarium and Pond Plants of the World, Edition 2," "Scale Insects-Identification Tools for Species of Quarantine Significance," and "Identification Tool for Weevil Biological Control Agents.”

- Achieved significant progress in utilizing hyperspectral imaging of taxonomically significant spectral patterns (from ultraviolet to infrared) within and among pest taxa for counting, sorting, and classifying trap sample specimens.

- Demonstrated practical levels of suppression of two highly invasive weeds (common tansy and cogongrass) with novel combinations of herbicide rates, spray additives, and application timing.

\section{CPHST Lab, Gulfport, MS}

\section{How We Support the Mission}

The Gulfport Lab consists of three sections: Analytical Chemistry, the Soil Inhabiting Pest Section (SIPS), and CPHST Quality Management. The analytical chemistry section conducts routine sample analysis for detecting the presence of pesticide residues and toxic substances. This work directly supports on-

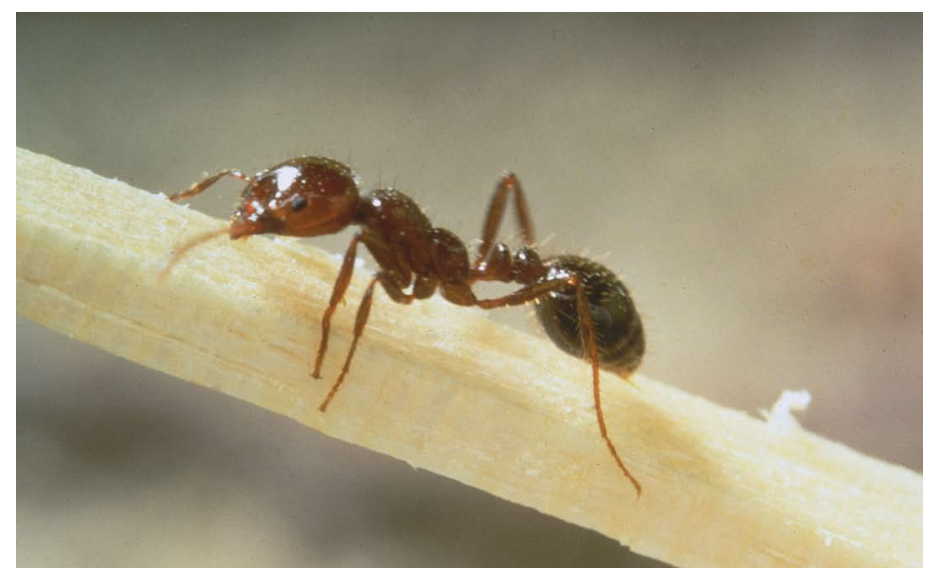

Figure 6-The red imported fire ant (Solenopsis invicta) is established across the South and hitchhiked into southern California in pallets of sod a few years ago. (APHIS file photo) 
going APHIS operational and emergency programs for such pests as Asian longhorned beetle (ALB), boll weevil, grasshopper, and fruit flies. In addition, the chemistry laboratory conducts multiple work projects that provide chemistry-based options for PPQ field operatives concerning the identification and detection of prohibited commodities or the detection of invasive insect species. SIPS develops methods and tools for the survey, detection, regulation, and control (both chemical and biological) of the imported fire ant (IFA) (fig. 6) and other soil-inhabiting pests. PPQ's State plant regulatory officials (SPROs), the nursery and chemical industries, farmers, homeowners, and other stakeholders utilize technology developed by the IFA section. The CPHST Quality Management section seeks to implement a quality management system for CPHST labs that meets or exceeds ISO requirements and obtains and maintains registration to the ISO standards. Employees in the Quality Management section work directly with the laboratories to facilitate initial ISO registration and continued compliance and maintenance of the ISO standards.

\section{Recent Accomplishments}

- Analyzed and reported 950 APHIS routine program support samples within stipulated deliverable times.

- Completed 900 project samples supporting APHIS initiatives.

- Achieved ISO 9000 registration in July 2007 for HPLCbased methods supporting APHIS' operational and emergency programs. The CPHST Mission Laboratory achieved ISO registration in March 2007.

- Issued USDA-APHIS Program Aid No. 1904 "Imported Fire Ant 2007: Quarantine Treatments for Nursery Stock and Other Regulated Articles" in December 2006.

- SIPS staff participated on the planning committee for the first International Pacific Invasive Ant Conference held in Kona, HI, May 22-25, 2007.

- Working with PPQ headquarters, regional, and State staff and APHIS-Investigative and Enforcement Services personnel, SIPS staff members presented training sessions to State inspectors in Georgia, Tennessee, and Oklahoma on the Federal IFA regulatory program, toured local nurseries, and held informational meetings with nursery growers in these areas.

\section{CPHST Lab, Mission, TX}

\section{How We Support the Mission}

A substantial portion of the work at the CPHST Mission Lab focuses on the development of molecular diagnostics of fruitfly pests and SIT support. Current studies are underway to develop molecular diagnostic techniques for Anastrepha, Bactrocera, and Ceratitis; fruit-fly SIT diet; and fruit-fly trapping and monitoring. These efforts are geared to provide effective SIT management options. Molecular diagnostics development is not restricted to fruit flies, however, and includes other arthropods and invertebrates such as thrips, slugs, and snails. Offshore initiatives include integrated pest management studies of chilli thrips, giant African snails, and Cuban slugs. The offshore work dovetails nicely with newly initiated molecular diagnostic work.

Remote sensing continues to be an important asset at the Mission Lab. Current studies use hyperspectral imaging and other remote-sensing technology to develop classification maps of ash trees in Michigan in support of APHIS' emerald ash borer (EAB) (Agrilus planipennis Fairmaire) eradication work.

Citrus plant health issues focus on citrus canker with special emphasis on infected fruit, and on the psyllid vectors for citrus greening (huanglongbing) in the Rio Grande Valley.

Our focus has changed over the past few years from one solely dedicated to biocontrol to a laboratory that is multifaceted in molecular biology, integrated pest management, plant disease epidemiology, and biocontrol. The laboratory continues to grow in these new directions in support of PPQ programs. 


\section{Recent Accomplishments}

- The Mission Lab used a molecular fingerprinting technique to assess the genetic variation in geographic populations of the Mexican fruit fly (fig. 7).

- We determined the efficacy of nine commercial molluscicide formulations against the Cuban slug (Veronicella cubensis) in Rota (Commonwealth of the Northern Marianas Islands).

- We developed a DNA-based method, using DNA barcodes, to identify immature LBAMs in California-the first time this method was used in the regulatory arena.

- We developed a DNA-based method to identify species of arionid slugs.

- We developed dispersion patterns and sampling plans for Asian citrus psyllid in south Texas.

- We completed epidemiologic field studies of cankered citrus and asymptomatic fruit.

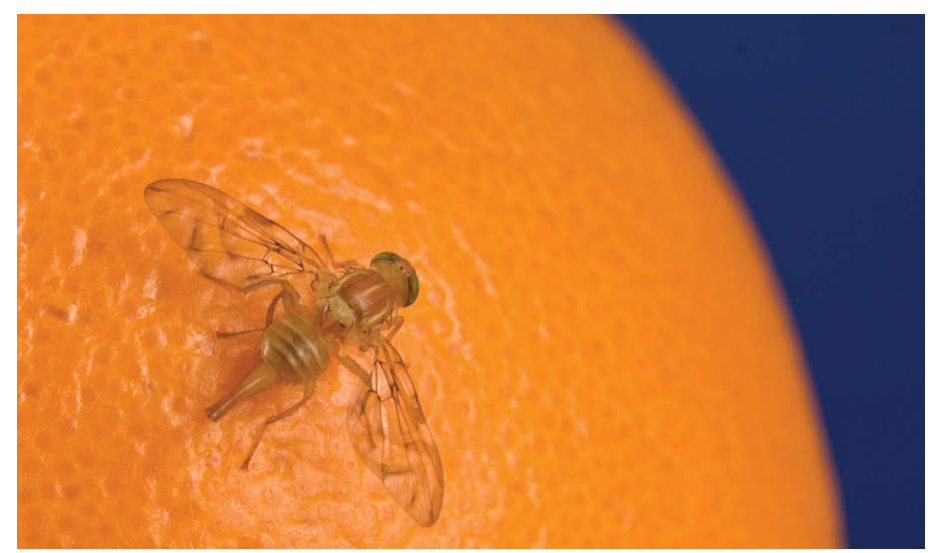

Figure 7-The Mexican fruit fly, a frequent hitchhiker on fruits imported from Central America. (Photo from the Division of Plant Industry archive of the Florida Department of Agriculture and Consumer Services and reproduced with permission.)

\section{CPHST Lab, Otis ANGB, Massachusetts}

\section{How We Support the Mission}

The Otis Lab's mission is to identify, develop, and transfer technology for survey, exclusion, control, and risk assessment for APHIS and its cooperators. The lab serves a wide variety of PPQ programs, including those to control or eradicate the ALB, EAB, Sirex noctilio, Asian gypsy moth (AGM) (fig.

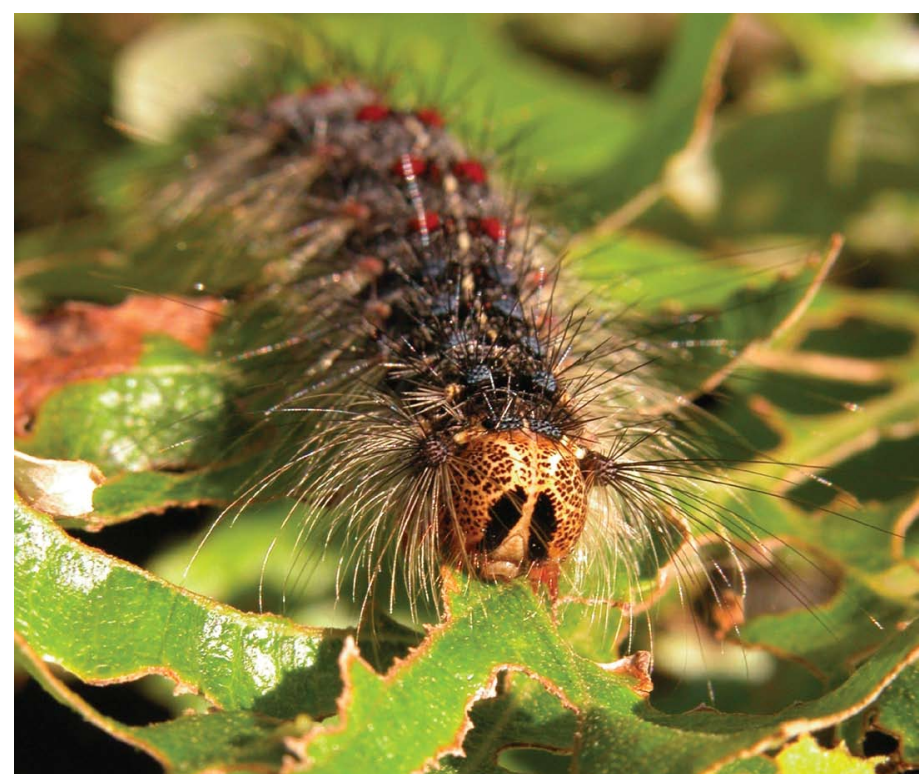

Figure 8-Late-instar larva of the Asian gypsy moth (Lymantria dispar) look just like the ordinary gypsy moth-only molecular analyses can distinguish the two related pests. (Photo by Ferenc Lakatos, University of West Hungary, reproduced with permission.)

8), and LBAM; exotic pest-detection programs; CAPS; and AQI commodity treatments. Otis personnel identify high-risk exotic pests and develop survey technology to facilitate early detection of introductions. In addition, we are carrying out projects in support of a risk assessment for Copitarsia and provide support for possible introductions of pests, such as khapra beetle, and development of targeted surveys for pests, such as the brown spruce longhorned beetle and swede midge. The laboratory also continues to support the gypsy moth program by creating risk maps, developing improved estimates of mate finding at low population densities, and producing the gypsy moth virus product, Gypchek. Additional work is centered on the development of regulatory treatments for various commodities or for means of conveyance (pallets, containers, etc).

The Otis Lab is developing rearing systems for the cactus moth (Cactoblastis cactorum) and the winter moth and biocontrol programs for the winter moth, EAB, and Sirex noctilio. Otis personnel maintain cooperative relationships with USDA's Agricultural Research Service (ARS), Forest Service, universities, and private industry. These cooperative projects extend to government organizations and universities in a number of foreign locations, such as Australia, Brazil, China, Japan, Korea, Russia, and South Africa. 


\section{Recent Accomplishments}

- Otis personnel obtained evidence that the EAB is resistant to the IPPC standard heat treatment ISPM-15 for wood packing material, which is exposure at $56^{\circ} \mathrm{C}$ for 30 minutes. These results are leading to development of a new heat-treating schedule for items that may be infested with EAB. This project will be completed in 2008 .

- We supported the LBAM program by leading a TWG and developing and evaluating control treatments, including mating disruption. Work is also underway to develop regulatory treatments for nursery stock and improve the standard lures for pheromone traps. The Otis Lab supplied more than 100,000 pheromone dispensers for use in California and other States.

- We released three exotic EAB parasites in plots in Michigan and discovered a fourth EAB parasite in the Russian Far East. Otis personnel helped with plans to develop a parasite production facility and release and evaluation programs. We tested additional insecticides and proved them to be effective to control EAB. Work continues to evaluate other pesticides. Otis developed a trap-lure combination and guidelines for its use and provided them to the EAB program for its survey work. The laboratory organized an annual EAB meeting in Pittsburgh to exchange current research findings within the $\mathrm{EAB}$ community. An EAB Science Panel meeting followed this meeting.

- We continued to carry out DNA analysis of all specimens submitted from PPQ's domestic monitoring program and developed new markers and a universal library of Lymantria specimens for AGM research support. We completed a long-term project through the publication "A review of selected species of Lymantria Hübner [1819]," by M. G. Pogue and P. W. Schaefer.

- We developed new immunoassays for additional alternative insecticides for ALB. We provided support to develop an attractant and traps for ALB survey. Recent advances in ALB rearing methods include an artificial substrate for oviposition (logs were used until now).

- We provided pheromone dispensers to support the national CAPS program and provided technical advice about trap design, placement, and survey strategies. Recently, this work included recommendations for surveys for wood borers, Spodoptera spp., the brown spruce longhorned beetle, and LBAM.
- In a cooperative effort with The Pennsylvania State University, we are developing remote sensors for detecting or monitoring pest populations. Good progress has been made with automated pest recognition and remote field-data reporting components of the project.

- We conducted experimental releases of a Sirex biocontrol agent (the nematode Beddingia siricidicola) in New York and Michigan. Studies to develop the methodology and timing for establishing trap trees for nematode release are yielding results. Studies are also underway to characterize the impact on native natural enemies.

- We evaluated host-plant volatiles of Sirex as attractants for traps. Electroantennogram studies have identified several active compounds. The presence of contact pheromone has also been documented, and we are exploring uses for it in survey or population management once it is chemically identified.

- Development of regulatory treatments for pine wood is progressing. Surprisingly, our 2006 host-tree studies showed that stressed white pines yielded as many $S$. noctilio as artificially stressed Scotch or red pine. White pine (Pinus strobus) was thought to be a nonhost or marginal host for $S$. noctilio.

\section{CPHST Lab, Phoenix, AZ}

\section{How We Support the Mission}

The CPHST Phoenix Lab's mission is to develop, adapt, and implement areawide control technologies for new and existing program pests. Current work includes developing control methods for the APHIS-PPQ Pink Bollworm (PBW) Eradication Program and grasshopper and Mormon cricket control programs using biotechnology, sterile insects, pheromone delivery systems, application technology, and GIS applications. Scientific staff at the Phoenix Lab conduct extensive field studies to test materials and validate methods.

The lab uses specialized equipment, including environmental chambers and portable mass-rearing modules, a twin-screw extruder for insect diet development, a room that allows for the simulation of aerial applications of sprayed products, a quarantine laboratory for rearing genetically modified (GM) PBW, and equipment for testing pesticide and pheromone application technology. In addition, the Phoenix personnel work closely with the PBW Rearing Facility to develop and test mass-rearing technology to implement improved methods on a large scale. 


\section{Recent Accomplishments}

PBW-

- We identified a sprayable PBW mating-disruption formulation that will significantly improve mating disruption in the field and save application costs (fig. 9). This formulation can be extended to other invasive pest species, such as LBAM and cactus moth.

- We developed a new egg disinfectant that provides an environmentally-friendly substitute for formalin in the PBW Rearing Facility. The new treatment will be used in the 2008 sterile-insect production season for the PBW eradication program.

- We conducted the first open field test of a PBW sterile marker strain genetically modified to express a fluorescent protein for potential use in the eradication program. Use of a genetic marker strain of PBW would allow error-free identification of released moths in monitoring traps. That, in turn, will improve program effectiveness.

- We designed and built a specialized stand-alone facility for mass-rearing and collecting quarantine-related moths. This facility can produce more than 500,000 genetically modified sterile PBWs a week for field testing. Also, this rearing unit could serve as a prototype for mass production for other lepidopteran pests.

- We developed a prototype nozzle that produces a large dollop for aerial spraying of pheromones. This nozzle promises major improvements in PBW and gypsy moth control programs.

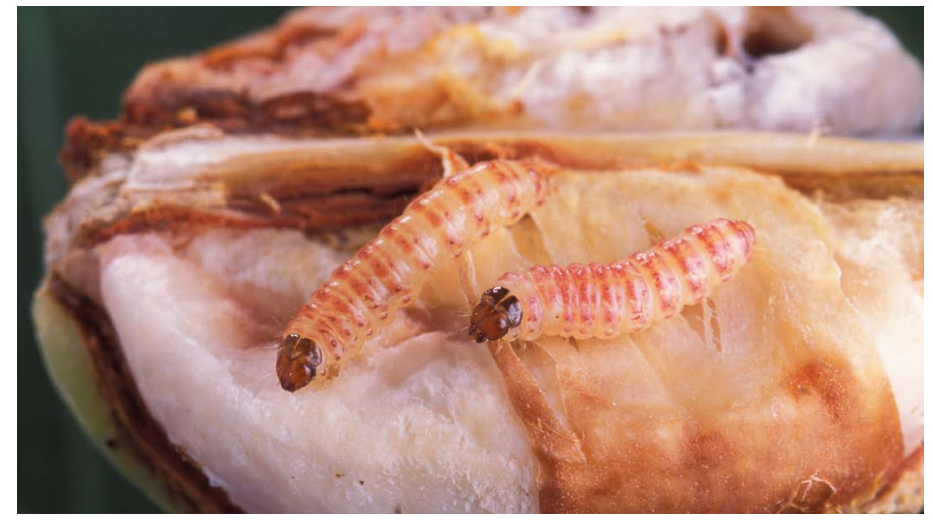

Figure 9-Larvae of the pink bollworm (Pectinophora gossypiella), a cotton pest in the Southwest. (USDA Agricultural Research Service [ARS] photo by Peggy Greb.)

\section{Grasshopper and Mormon Cricket-}

- We developed an economical system to evaluate potential fungal pathogens for rangeland grasshoppers. The system consists of technology that simulates aerial field application by spraying from a tower and field cages designed to allow normal thermoregulation of grasshoppers.

\section{CPHST Plant Epidemiology and Risk Analysis Laboratory (PERAL), Raleigh, NC}

\section{How We Support the Mission}

PERAL is PPQ's primary location working on Pest Risk Assessment (PRA) methodology. In this lab, a diverse group of scientists and professionals provides essential scientific support to risk-based policymaking across a broad range of phytosanitary issues. We use sound science to analyze both import and export issues and facilitate safe trade. Our PRAs help safeguard American agriculture and plant health from harmful exotic plant pests in both managed and unmanaged ecosystems. PERAL personnel perform most risk analyses required by PPQ for pests, commodities, and pathways. More specifically, our analyses help PPQ to design risk-based regulations for exotic and domestic pest-management programs, identify and assess new pest threats, monitor the effectiveness of existing programs, and optimize available resources to enhance protection.

\section{Recent Accomplishments}

- PERAL personnel finalized 26 PRAs in fiscal year (FY) 2007 for 31 commodities from 36 different countries, or a total of 72 new country-commodity combinations.

- We completed 16 analyses supporting U.S. export issues, such as Pacific Northwest apples to Taiwan (codling moth) and wheat to the European Union (Karnal bunt).

- We completed 13 organism analyses, and the New Pest Advisory Group (NPAG) closed 58 pest files in FY 2007, 31 of which were for pests new to the United States.

- We completed a PRA for armored scales on imported fruit for consumption.

- We finalized PRAs supporting PPQ rulemaking that will allow safe transport of Hawaiian solid waste in airtight bales to landfills in Idaho and Oregon. 
- We completed an experimental analysis of the rate of fruit-fly emergence from composted fruit.

- We completed a PRA for asymptomatic fruit (citrus) which allowed for citrus to move from Florida to noncitrus-producing States.

\section{Biological Control Unit (BCU), Raleigh, NC}

\section{How We Support the Mission}

The BCU—a virtual team of 10 to 12 CPHST scientistsfocuses on developing technologies that allow living biological organisms (e.g., natural enemies and competitors) to lessen the impacts of introduced, invasive insect pests, weeds, and plant pathogens. Use of these organisms also minimizes impacts on the environment and nontarget organisms. The BCU strives to better prepare the agency for potential incursions of exotic pests and effective pest-management options. BCU scientists provide technical oversight and expertise to programs to ensure that gaps in scientific knowledge are identified and eliminated and that new information is rapidly transferred to stakeholders. The BCU also provides support in the discovery and evaluation of new biocontrol agents offshore and domestically and develops cost-effective rearing and monitoring systems for approved biocontrol agents and their hosts. In addition, the BCU provides permitted biocontrol agents collected from established field insectaries to PPQ project managers and other project cooperators, ensures the safety of biocontrol agents by continued postrelease monitoring, and develops educational and programmatic materials for use by PPQ and other collaborators.

\section{Recent Accomplishments}

- BCU personnel evaluated the EAB parasitoid Spathius agrili (Hymenoptera: Braconidae), in collaboration with China, for release in Michigan.

- We established a colony of the insect-eating nematode Beddingia siricidicola in support of potential future release efforts and conducted a controlled field release to assess its impact on Sirex noctilio woodwasp under local conditions.
- We collected more than 100,000 adult saltcedar leaf beetles (Diorhabda elongata) in Nevada and distributed them for field release at 35 field insectary sites in 10 States.

- We completed a field study examining how the field bindweed mite (Aceria malherbae) uses native bindweeds. Preliminary results indicate that native bindweeds seem to be poor hosts for the mite and may be at little risk for nontarget attack.

- In collaboration with cooperators at Florida A\&M University and in the Caribbean, we discovered a complex of natural enemies, including two commercially available parasitoids (fig. 10) that are able to maintain passion vine mealybug (Planococcus minor) at very low, non-pest levels in Trinidad. These natural enemies could serve as potential biocontrol if the pest became established in the United States.

- In looking for a natural enemy that could control tropical soda apple, we found a beetle (Gratiana boliviana) that eats the weed's leaves and can persist through two winters in Alabama and Georgia. We initiated releases of beetles in Texas and continue to monitor their impact.

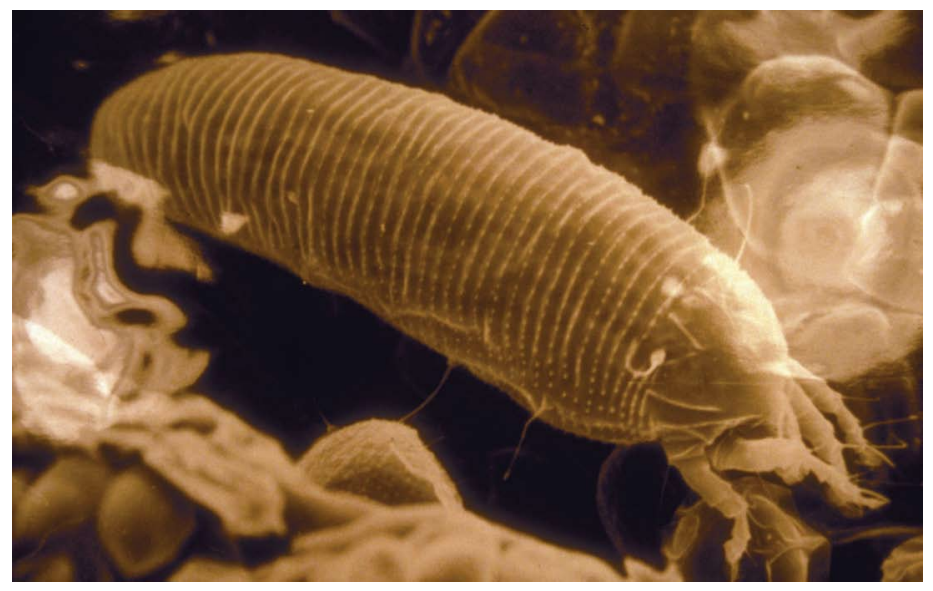

Figure 10-The bindweed gall mite is one of two parasitoids that have successfully controlled passion vine mealybug in Trinidad. (USDA ARS file photo.) 
- BCU personnel planned and delivered a workshop hosted by PPQ's Western Region in Fort Collins, CO, to provide State Plant Health Directors and their staff with an overview of biocontrol principles and concepts that guide PPQ programs.

\section{Treatment Quality Assurance Unit (TQAU), Raleigh, NC}

\section{How We Support the Mission}

TQAU works to safeguard American agriculture and natural resources by developing, adapting, and supporting technology to detect, identify, and mitigate the risk posed by exotic pests in preclearance programs, in National Plant Protection Organization (NPPO) countries, and at U.S. ports-of-entry (fig. 11). APHIS' last line of defense against an exotic pest invasion is the commodity treatment that mitigates this risk. Currently, core activities within TQAU include developing quarantine treatments, contributing to the PPQ treatment manual for ports-of-entry, certifying shipping containers and vessels, maintaining databases for methyl bromide and in-transit cold treatments, training-the-trainer for proper application of treatments and certification of international commodity treatment facilities within foreign countries, and conducting treatment quality-assurance audits on cold and methyl bromide treatments. Commodity treatments are conducted by NPPO officers and APHIS-PPQ and International Services personnel at foreign sites.

\section{Recent Accomplishments}

- TQAU personnel developed an electronic system to track information on commodity treatments. The system consists of databases including the 429 fumigation, 556 cold treatment and irradiation treatments used on inbound vegetables and fruits.

- We reviewed and provided recommendations on commodity treatment research (both new and currently used).

- We performed audits on nonchemical treatments (e.g., those employing hot water, vapor heat, or cold) and chemical treatments (e.g., methyl bromide and phosphine).

- We certified about 65 vessels and 64,000 containers for in-transit cold treatments.

- We trained NPPO officers from Turkey, Egypt, and India on how to perform cold treatments and how to use the 556 cold treatment database.
- TQAU personnel successfully tested the real-time remote-monitoring data upload for the 556 cold treatment database on 6 containers during transit. (This database is being used in eight countries by APHISInternational Services and/or NPPO workers.)

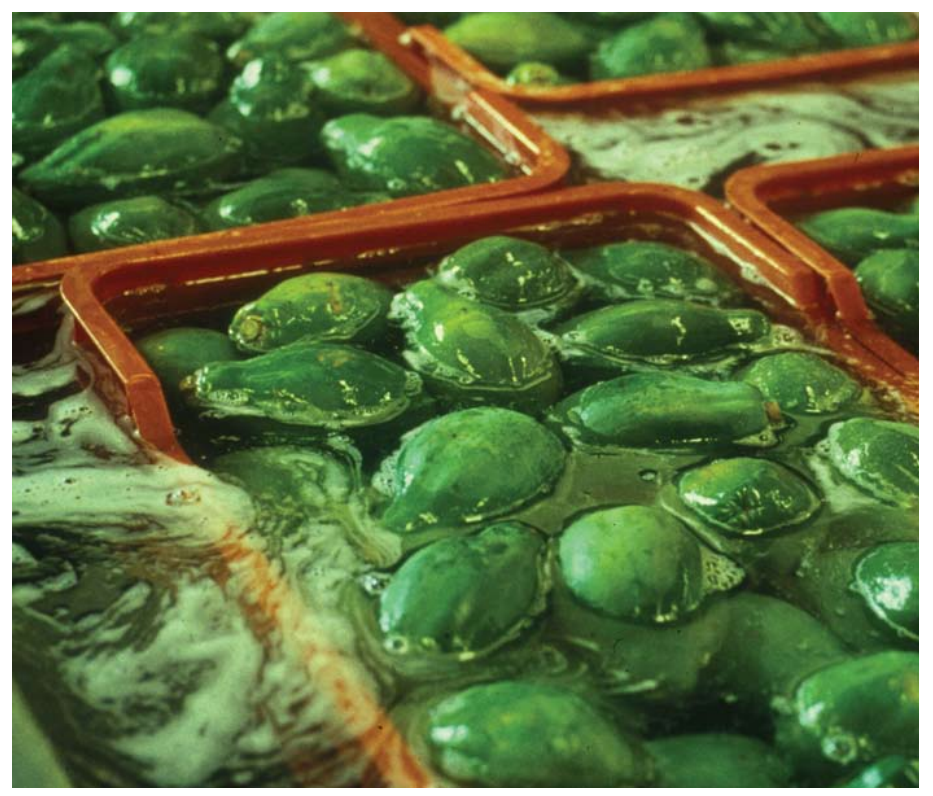

Figure 11-Pretreating mangos in Mexico using hot water and following APHIS protocols makes the fruit safe for importation. CPHST-TQAU helped develop these protocols. (USDA APHIS file photo.) 



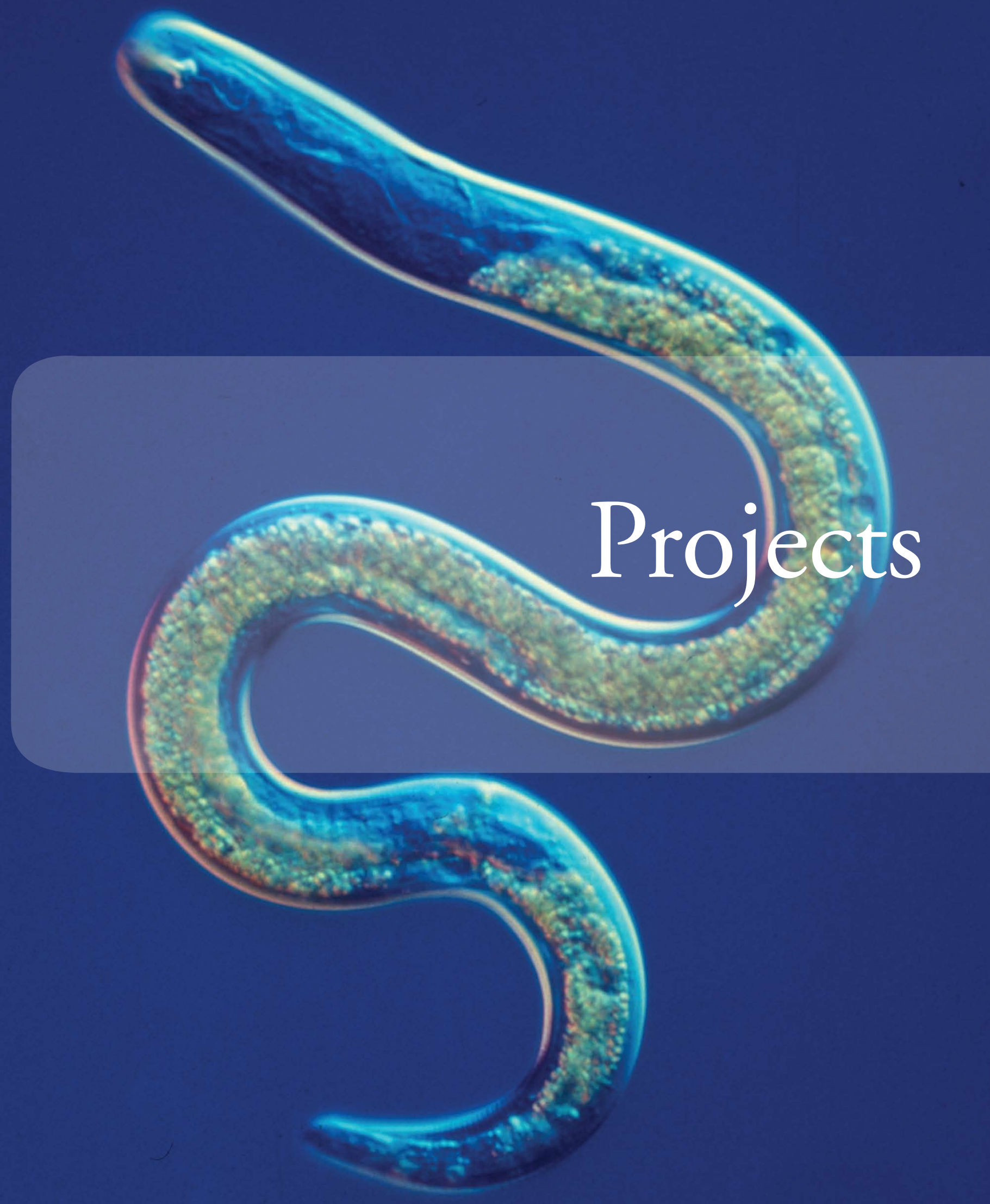




\section{Development and Validation of PCN Detection Protocols \\ Location: CPHST Lab, Beltsville, MD}

On April 19, 2006, APHIS announced the detection of the pale PCN, a major pest of potato crops, in Idaho. This was its first detection in the United States. Under a Federal Domestic Quarantine Order, workers from APHIS-PPQ and Idaho's department of agriculture began a survey of fields where the presence of PCN was suspected. Morphological identification of PCNs can be difficult. Quick, sensitive, and accurate methods were necessary to detect this important potato pest. Researchers at USDA-ARS' nematology lab in Beltsville, MD, made available conventional PCR detection methods. In 2007, we validated the most reliable published molecular diagnostic assays (conventional PCR), as well as PCR-based assays to differentiate $G$. pallida from both $G$. rostochiensis and $G$. abacus (fig. 12). We also adapted these PCR-based detection protocols for widescale national survey by developing a rapid nematode sample-preparation and DNA-extraction method. The new extraction method reduced the risk of contamination when handling large numbers of samples and eliminated the need for single nematode extraction, which is time-consuming and requires the intensive use of a microscope.

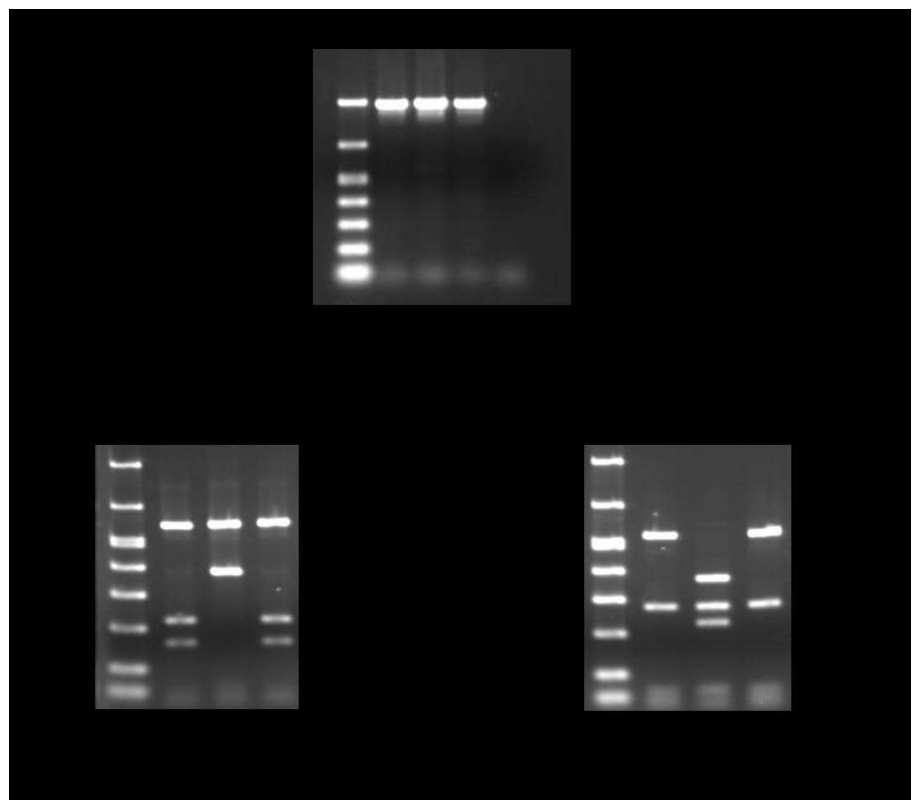

Figure 12-A validated PCR assay such as this can differentiate Globodera pallida - the PCN - from other Globodera species. (Photo by USDA APHIS, CPHST lab in Beltsville.)
The validated PCR-based protocols provide sensitive, rapid, and accurate diagnostic technology. Through hands-on training, our Beltsville Lab transferred this technology to the PPQ Plant Health Programs' Molecular Diagnostic Laboratory. Beltsville personnel will also transfer the technology to other PPQ and accredited National Plant Diagnostic Network laboratories.

To reduce the complexity of the diagnostics, we also evaluated a previously published real-time SYBR Green PCR protocol. That evaluation led us to further analyze published sequences of the internal transcribe spacer (ITS) region of several Globodera species. To increase the sensitivity and specificity of detection, we developed two real-time TaqMan PCR assays. The new PCR assays detect the genus Globodera and differentiate G. pallida from G. rostochiensis and G. tabacum (fig. 13). We will validate the developed real-time PCR protocols and deliver a training program on them in 2008.

TaqMan Real-Time PCR for the Detection of Globodera spp.

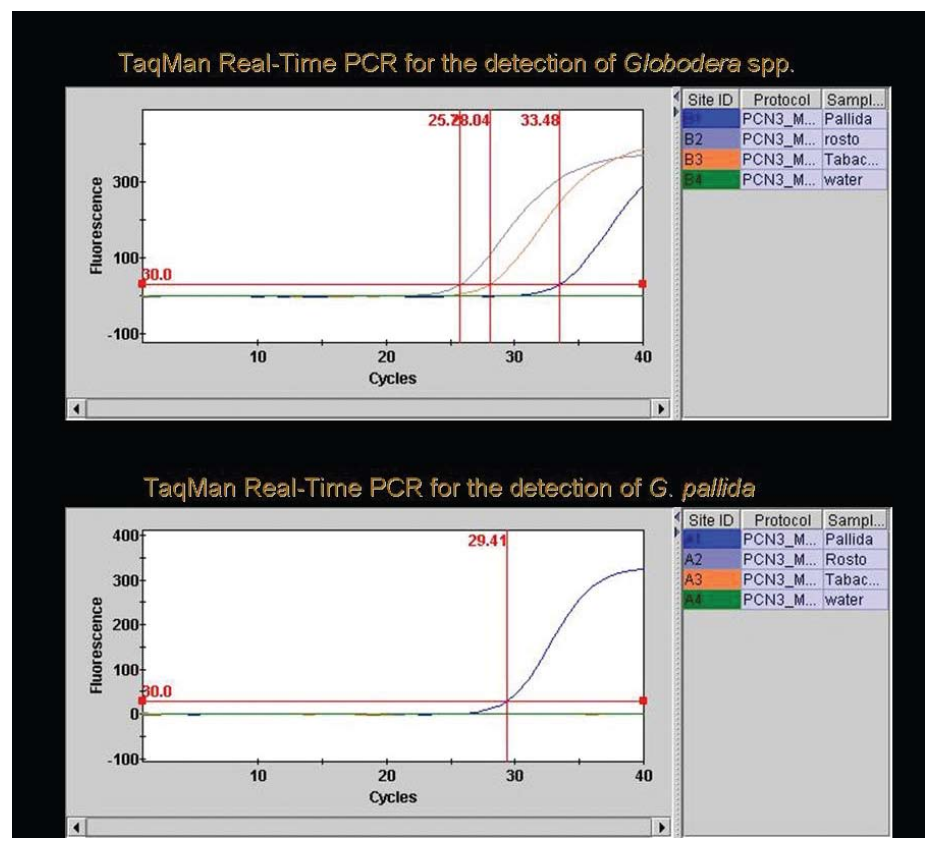

Figure 13-Real-time PCR assay to detect Globodera and differentiate the PCN species from others, as executed by the CPHST Beltsville Lab. 


\section{Electronic Identification Tools for Pest Detection \\ Location: CPHST Lab, Fort Collins, CO}

Identifying invasive pests and, importantly, distinguishing them from nonpests, is a continuing need inside the United States, at U.S. ports-of-entry, and offshore. Various automated tools could facilitate identification by APHIS personnel with different job responsibilities and levels of expertise. Electronic, matrix-based keys are an exciting, recently developed identification technology that can be used in several ways for different purposes (fig. 14).

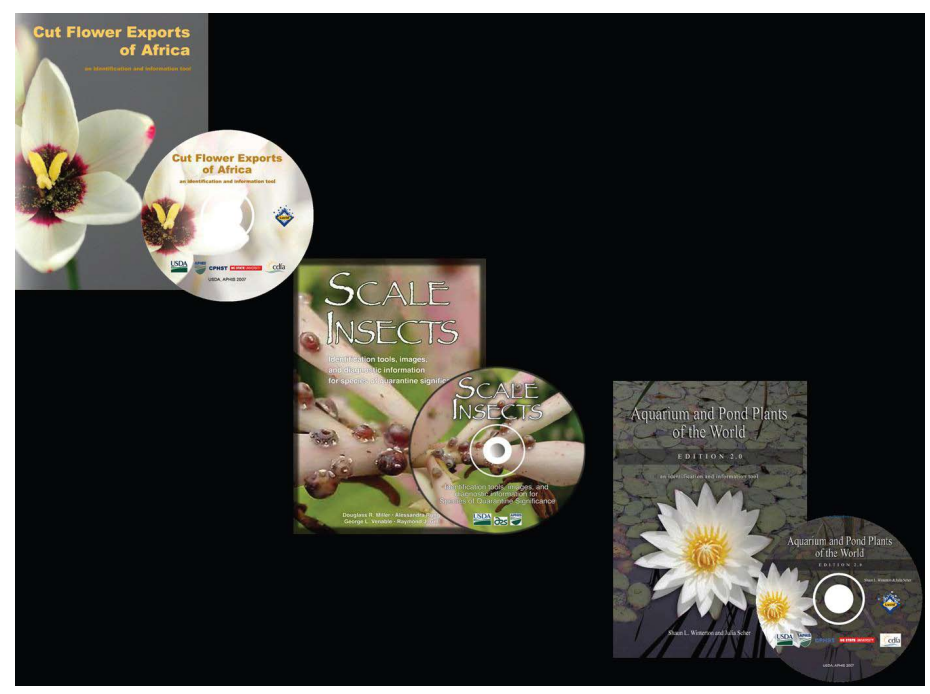

Figure 14-Lucid CDs produced by the CPHST Fort Collins Lab.

Fundamentally different from traditional, paper-based dichotomous keys, matrix keys let users choose characters in any order and choose or ignore any given character. A wealth of associated media, such as factsheets, drawings, and photographs, can be attached to the characters and taxa in the key. A matrix key can be just one part of a comprehensive Web site (e.g., a site studying a particular genus or a specific commodity). The number of matrix keys produced worldwide is growing rapidly; matrix keys may evolve to become the identification key format of choice.

CPHST has used Lucid ${ }^{\mathrm{TM}}$ software to develop a number of matrix-based identification tools, "Lucid tools," to help meet APHIS' diverse identification needs. Lucid software is the most widely used key-building software, both nationally and internationally. Lucid tools can be used for quick identification or verification, as a source of informational factsheets, and as an image gallery. CPHST continues to develop Lucid tools that can be used by novices and experts and can enhance and complement existing paper-based identification resources (fig. 15).

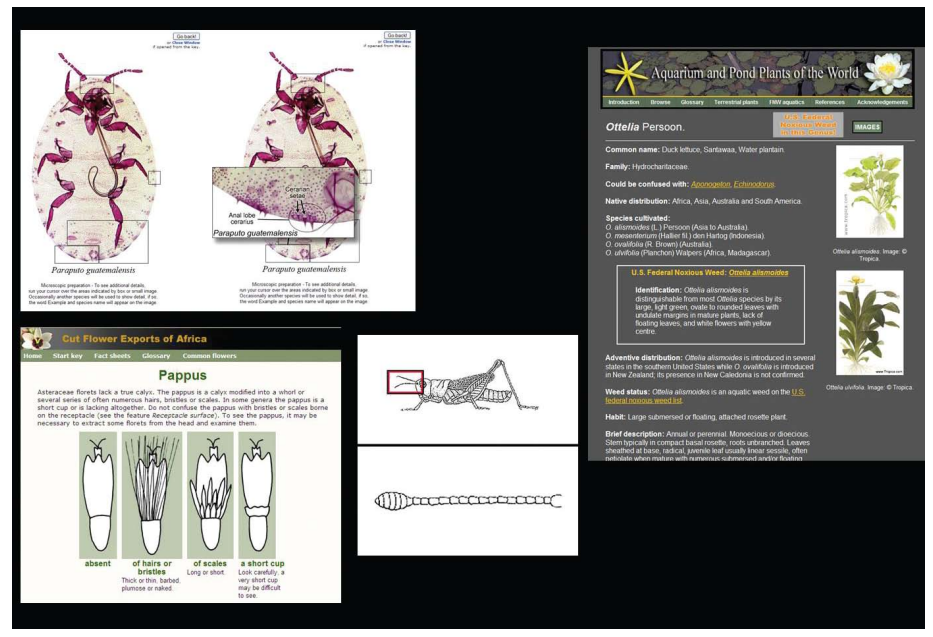

Figure 15-Lucid taxon images and factsheets also created by CPHST Fort Collins personnel.

CPHST locates taxonomic experts to become Lucid tool authors and, in the process, establishes collaborations with various academic institutions and governmental agencies. CPHSTproduced Lucid tools are peer reviewed and published on the Internet and on compact disc (CD). In 2007, CPHST delivered a number of Lucid tools to PPQ and its cooperators.

"Aquarium and Pond Plants of the World, Edition 2," which continues to be one of the most popular and widely used of our tools, was released on the Internet and on CD. "Cut Flower Exports of Africa," published on the Internet in 2006, is now available on CD. These two tools were developed in collaboration with the California Department of Food and Agriculture. "Scale Insects_-Identification Tools for Species of Quarantine Significance," a collaboration with USDA-ARS and the University of Maryland, was published on the Internet and put on CDs. "Scale Insects" was used in August 2007 during a scale and mealybug identification workshop held in the Caribbean that was sponsored by the NPDN and USDA-APHISInternational Services. This excellent tool is becoming a vital resource for those trying to identify an unknown scale. Other collaborations, with Florida A\&M University and the University of Nebraska, produced "Identification Tool for Weevil Biological Control Agents" and "Common Grasshoppers of the Western U.S., Edition 2," respectively. "Common Grasshoppers" was recently used during PPQ workshops CPHST conducted in summer 2007 in which participants learned how to use a Lucid tool. 
CDs of CPHST-produced Lucid tools are available from Terrence Walters (terrence.w.walters@aphis.usda.gov); CPHST Lucid tools online can be found at http://www.lucidcentral.org.

\section{Biological Control of Imported Fire Ants (IFAs) Using Phorid Flies: Cooperative Rearing and Release Project \\ Location: CPHST Lab, Gulfport, MS}

The IFA has been in the southern part of the United States for almost a century. IFAs are a public nuisance because of their painful sting and damage to some agricultural commodities and ground-dwelling reptiles, birds, and mammals. Different control and treatment measures and a 1958 Federal Quarantine have been implemented. A 1999 APHIS survey of Southern States, however, ranked this insect as a top priority for biocontrol management. IFA populations in its native environment (South America) are one-fifth the density that they are in the United States. Phorid flies, Pseudacteon spp., from South America are the most promising biocontrol agent for IFA, with as many as 15 species or biotypes that will affect IFA. We anticipate that the flies will be an important tool in the management of IFA, not a stand-alone control tool. The use of a suite of biocontrol agents for IFA will allow native ants to compete with IFAs for food and territory, allow fewer insecticide treatments to control IFAs, and suppress the IFA to an acceptable level.

APHIS funding for this project was initiated through CPHST's National Biological Control Institute in 2001 and is supported annually by PPQ-headquarters, Eastern Region, Western Region, and CPHST. The CPHST Gulfport Lab coordinates all phorid fly rearing schedules, species distributions by geographic location, fly releases, and population monitoring among participating States.

Using Phorid flies to manage IFA populations requires a complex interplay among various agencies here and abroad. ARS' Center for Medical, Agricultural, and Veterinary Entomology in Gainesville, FL, explores South America to find native populations of Phorids and imports them, oversees preliminary releases, and develops rearing techniques. Then the Center transfers the rearing technology to the Florida Division of Plant Industries (DPI), an agency of the Florida Department of Agriculture and Consumer Services. Through a cooperative agreement managed by PPQ's Eastern Region, DPI's Bureau of Methods Development and Biological Control rears the Phorids and ships them to cooperators. (See this Web site for more details: http://www.doacs.state.fl.us/pi/methods/firephorid.html.) State cooperators then release the flies and monitor the success of the releases.

The target goal is for each State to have two to seven successful releases per species, depending on the State's IFA quarantine area. Rearing of Pseudacteon tricuspis was initiated in 2001 with the first releases in 2002. Rearing of P. curvatus was initiated in late 2002 with the first releases in 2004. Rearing of a third species, P. obtusus was initiated in 2006 and releases will begin in 2008. Success is currently defined by overwintering at a site; however, success may not be known for 2 to 3 years after release, when fly populations are large enough to detect.

In coming years, the use of the Phorid fly trap to monitor populations will greatly enhance scientists' understanding of fly establishment and spread. We have collected release-site establishment data from most of our cooperators through the 2005 releases and have collected and compiled spreadsheet data from about 60 percent of our cooperators (fig. 16). The Phorid flies' impact on the IFA will not be known for many years, and more than two to three fly species will be needed for this biocontrol agent to achieve its full potential.

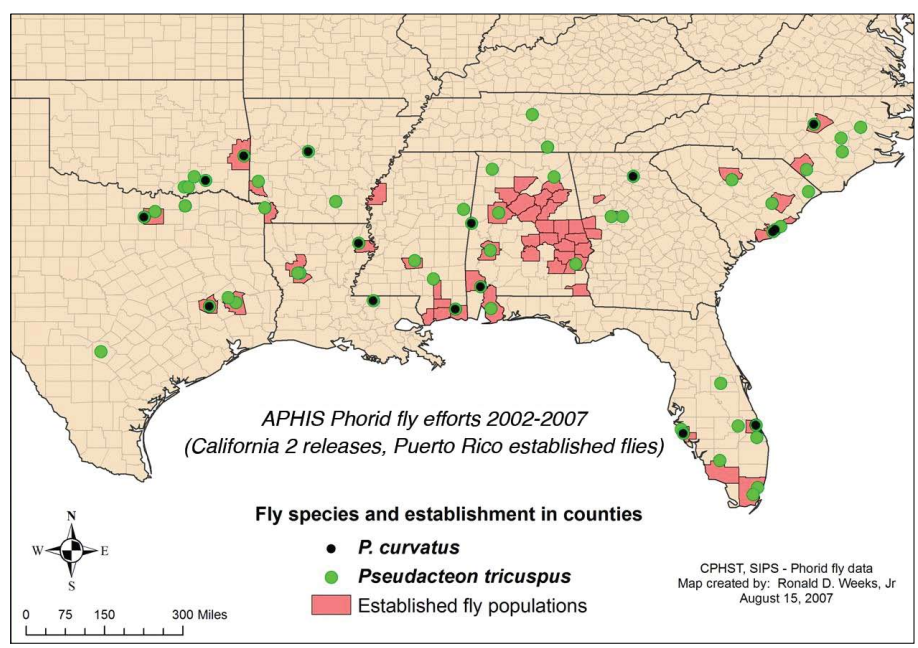

Figure 16-APHIS released phorid flies in the South over a 5-year period, and later surveys (pink zones) indicate that the flies had established populations near most of those releases. Dates are not complete on this map, however. California had two releases but no establishments so far. Puerto Rico had three releases, and all three led to established local phorid populations. 


\section{Results to Date}

- 79 total APHIS releases 2002-September 2007 (all species)

- 56 P. tricuspis releases 2002-September 2007

- 23 P. curvatus releases 2004-September 2007

- 27 of 56 (48 percent) releases in 2002-05 have overwintered (= successful release)

- 19 of 46 (41 percent) of $P$. tricuspis

-8 of 10 (80 percent) of $P$. curvatus

\section{Chilli Thrips (Scirtothrips dorsalis Hood), a New Invasive Pest in the United States Location: CPHST Lab, Mission, TX}

Chilli thrips is a tiny plant pest that feeds on flowers, leaves, shoots, and young fruits (fig. 17). More than 100 plant species from more than 40 plant families in Asia, Africa, North America, Eastern Europe, and Oceania have been reported as suitable hosts for this pest. An economic analysis by CPHST indicates that, in the United States, chilli thrips could cause losses ranging in value from about $\$ 3$ billion to $\$ 6$ billion.

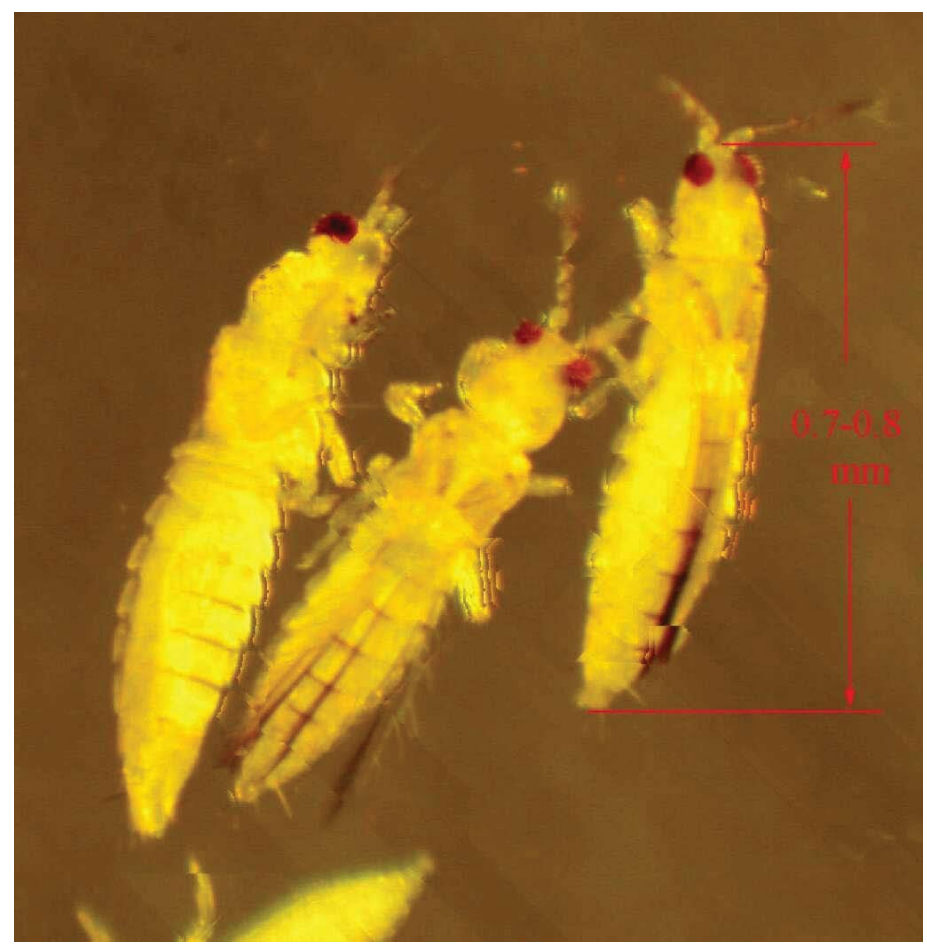

Figure 17-Chilli thrips (Scirtothrips dorsalis). (USDA APHIS photo by CPHST Mission Lab.)
Surveys by CPHST scientists from the Mission Lab done in the Caribbean show that chilli thrips has become established in St. Vincent, St. Lucia, Trinidad, Barbados, and Suriname. Further collaboration with ministries of agriculture in the Caribbean has shown that chilli thrips can cause significant economic losses in hot peppers, Sea Island cotton, and cucurbit crops (fig. 18) and scarring damage and yield loss in table grapes in Venezuela. Current reports from Florida indicate that chilli thrips poses a serious economic threat to the ornamental and landscape plant industries and causes damage to roses, ligustrum, and Indian hawthorne.

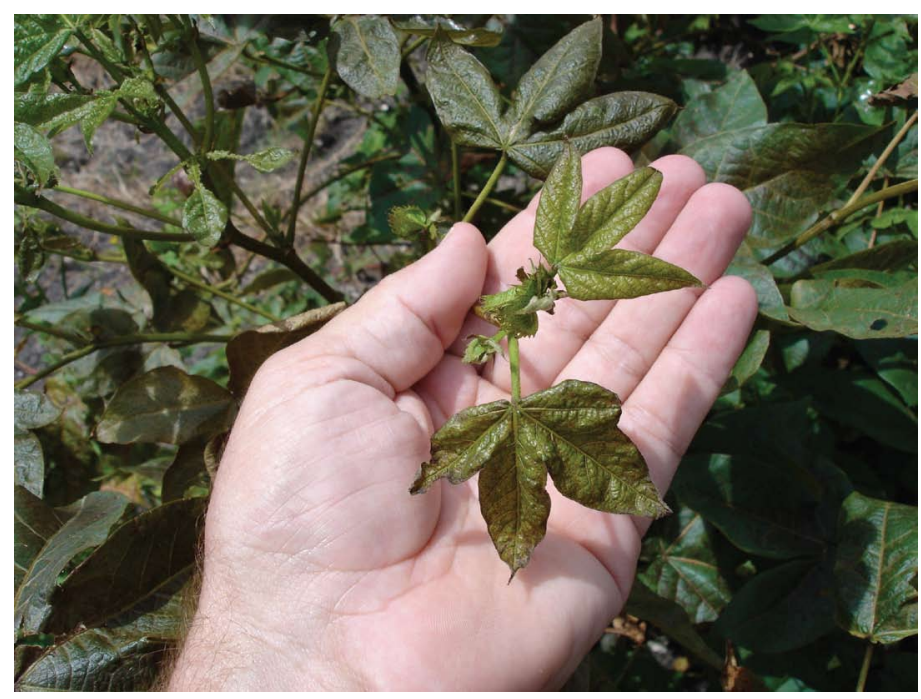

Figure 18-Chilli thrips caused damage to terminal cotton leaves with bronzing. (USDA APHIS photo by CPHST Mission Lab.)

CPHST-PERAL conducted a pathway analysis for chilli thrips and determined that air passengers and permitted cargo from the Caribbean region are the most likely means of introduction for chilli thrips into the continental United States. The insect could produce up to 18 generations a year in semitropical parts of the country and would likely survive in the southern and western coastal plains. In 2005, chilli thrips was found in 16 counties in Florida, in retail garden centers in Texas, and on roses in wholesale nurseries in Puerto Rico. These findings suggest that chilli thrips is currently moving through interstate agricultural commerce in the United States.

Identifying chilli thrips has proven to be difficult due to their minute size and similarities in appearance to other thrips. Adult specimens may be identified by physical characteristics; however, this technique is time consuming and requires considerable taxonomic expertise. Molecular-based methods provide a means for precise identification of difficult-to-identify species and specimens at immature stages of their life cycle. 
The genetics unit of the CPHST Mission Lab has closely examined both DNA sequence data and PCR-based methods for chilli thrips. Comparing DNA sequence data from diverse worldwide chilli thrips populations has provided insight into the genetic relatedness of these groups. This genetic information will be useful in determining the pest's country of origin to identify future biocontrol agents and in developing potential population markers.

The genetic variation in DNA sequences observed among species of thrips was useful for designing a diagnostic PCR assay producing a DNA marker for chilli thrips (fig. 19). The reliability of this diagnostic marker was demonstrated by screening 15 chilli thrips populations representing a broad geographic range. This diagnostic assay provides a quick and straightforward molecular technique for identification of the pest. Furthermore, the simplicity of the assay allows ease of transfer to other laboratories and offers the potential for field detection of this species.

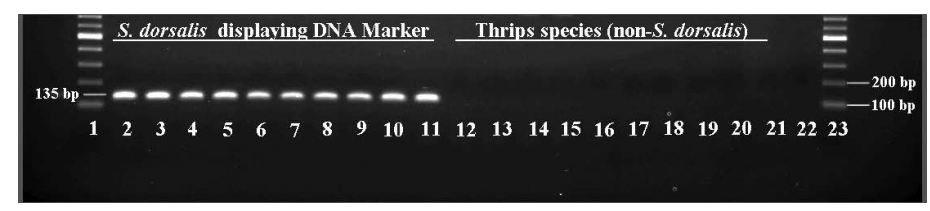

Figure 19-Agarose gel showing the PCR results from the chilli thrips diagnostic assay on six species of thrips. The DNA marker (135 bp fragment) was successfully produced from the chilli thrips individuals representing the geographic populations from Japan, India, Thailand, Barbados, and Puerto Rico (lanes 2-11), while the other thrips species did not produce the marker (lanes 12-21). Lanes 1 and 23, DNA standard ladder. Lanes 12 and 13, Scirtothrips citri. Lanes 14 and 15, S. perseae. Lanes 16 and 17, Thrips palmi. Lanes 18 and 19, T. tabaci. Lanes 20 and 21, Frankliniella occidentalis. Lane 22, negative control.

\section{Development of Survey Tools for the Emerald Ash Borer Location: CPHST Lab, Otis, MA}

The EAB is an East Asian wood borer that attacks ash (Fraxinus spp). A population of EABs was discovered in May 2002 throughout several thousand square kilometers of the metropolitan area in and around Detroit, MI, and Windsor, ON, Canada. Subsequently, infested ash trees were found in Ohio, Maryland, Virginia, Indiana, Illinois, Pennsylvania, and West Virginia (fig. 20). The beetle has killed an estimated 15 million ash trees in forested and urban areas in southeastern Michigan alone.

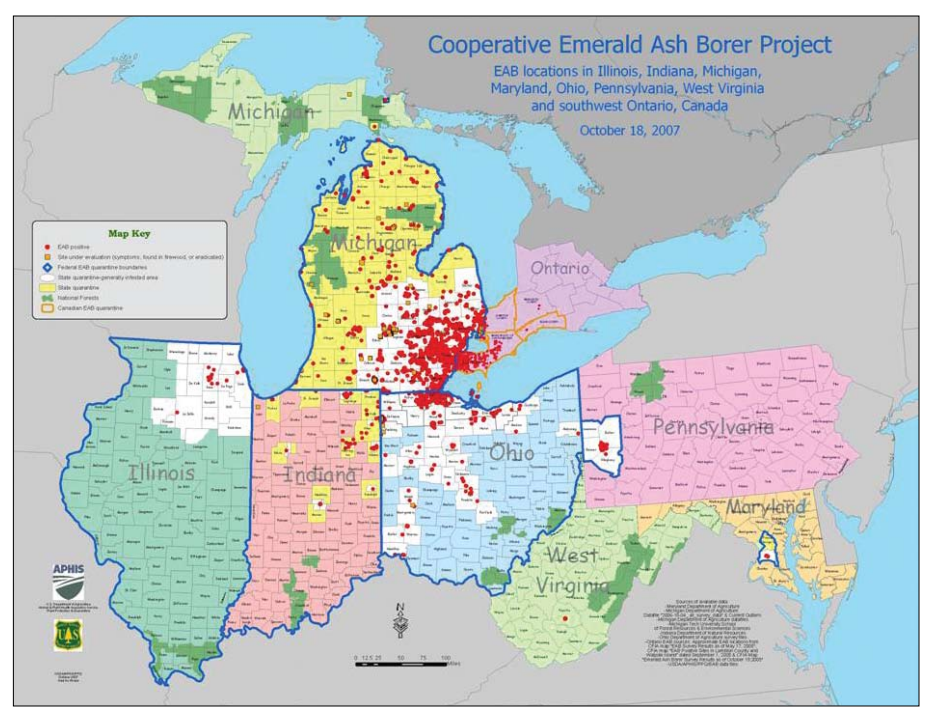

Figure 20-Current distribution of the EAB in North America.

Surveys for EAB were originally based on the presence of visual symptoms, such as adult exit holes, bark cracks, epicormic branching, and woodpecker feeding sites (fig. 21). Overall, survey results were poor, and newly infested areas often went undiscovered. Artificially stressed (girdled) trap trees offered an alterative to visual survey and were adopted programwide in 2005. Trap trees, however, are expensive to establish and evaluate, and their use poses liability problems for workers and the public.

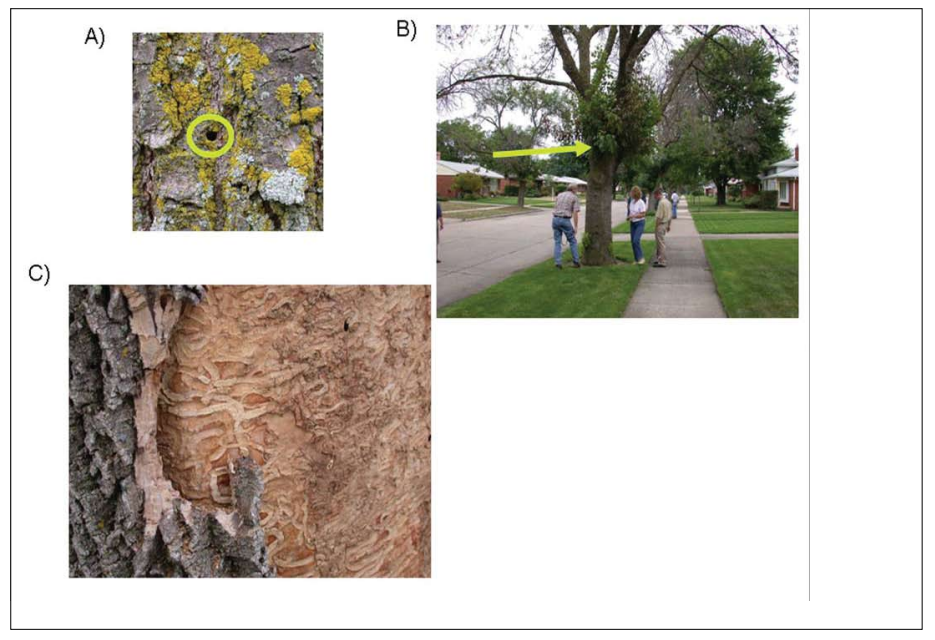

Figure 21-Symptoms of EAB attack used in visual surveys: $(A)$ D-shaped exit hole, (B) epicormic branching, and (C) larval galleries under the bark. 
The key to an effective management program for EAB is a survey program equipped with sensitive tools for detecting and delimiting populations. Three CPHST scientists, working with the assistance of the staff of the PPQ EAB laboratory in Brighton, MI, sought to design an efficient, easily deployable, and relatively inexpensive trap and lure for survey and detection of EABs. Some Agrilus species use visual, auditory, and/or semiochemical cues to locate hosts and potential mates. Potentially, such cues could be used to attract EABs to traps. The CPHST-PPQ collaborators also found that vertical placement of traps affects capture of some insects, including Agrilus spp. PPQ conducted field studies to determine optimal trap placement and design. Traps in the mid-canopy (at $13 \mathrm{~m}$, or $40 \mathrm{ft}$, aboveground) caught more than traps at breast height. Traps were also more effective when placed along forest edges or in adjacent fields, where they were exposed to more sunlight.

A three-sided prism trap (fig. 22) that provided a large trapping surface $(0.63 \mathrm{~m} 2)$ was developed and tested alongside several other designs that were used in previous Otis Lab EAB studies. The prism performed more effectively than a crossvane trap made of the same material, perhaps because the flat surfaces of the prism allowed light to reflect uniformly off its surface. Among several flat-paneled traps, there were no differences in catch, but the prism trap is the easiest to use, as it can be machine-cut out of a single sheet of plastic and is easily deployed in the mid-canopy (fig. 23).

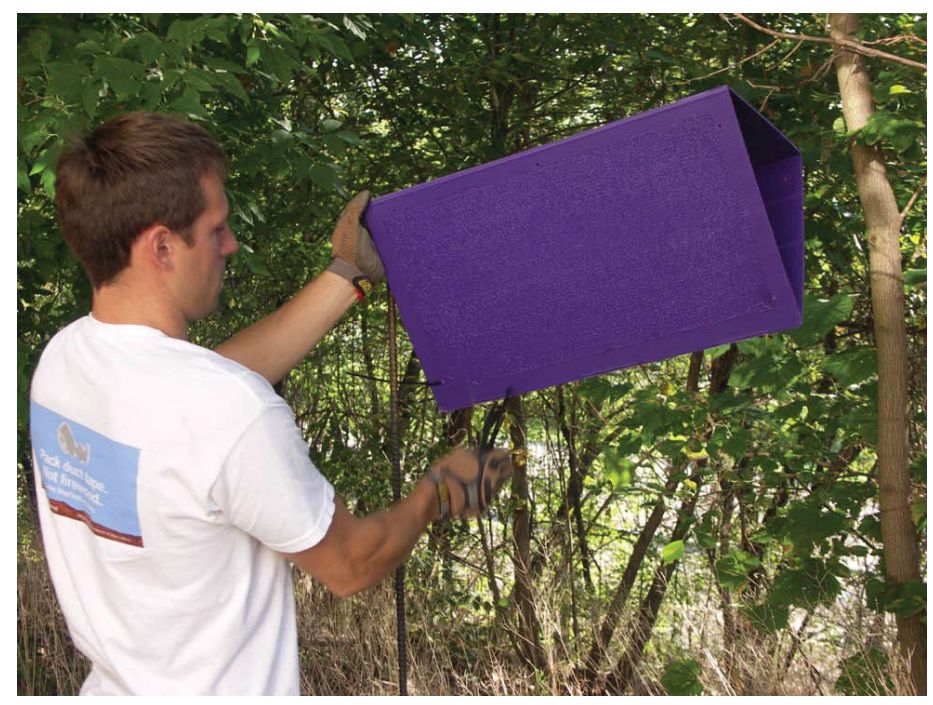

Figure 22-Closeup of the purple prism trap, hung at $1.5 \mathrm{~m}$.

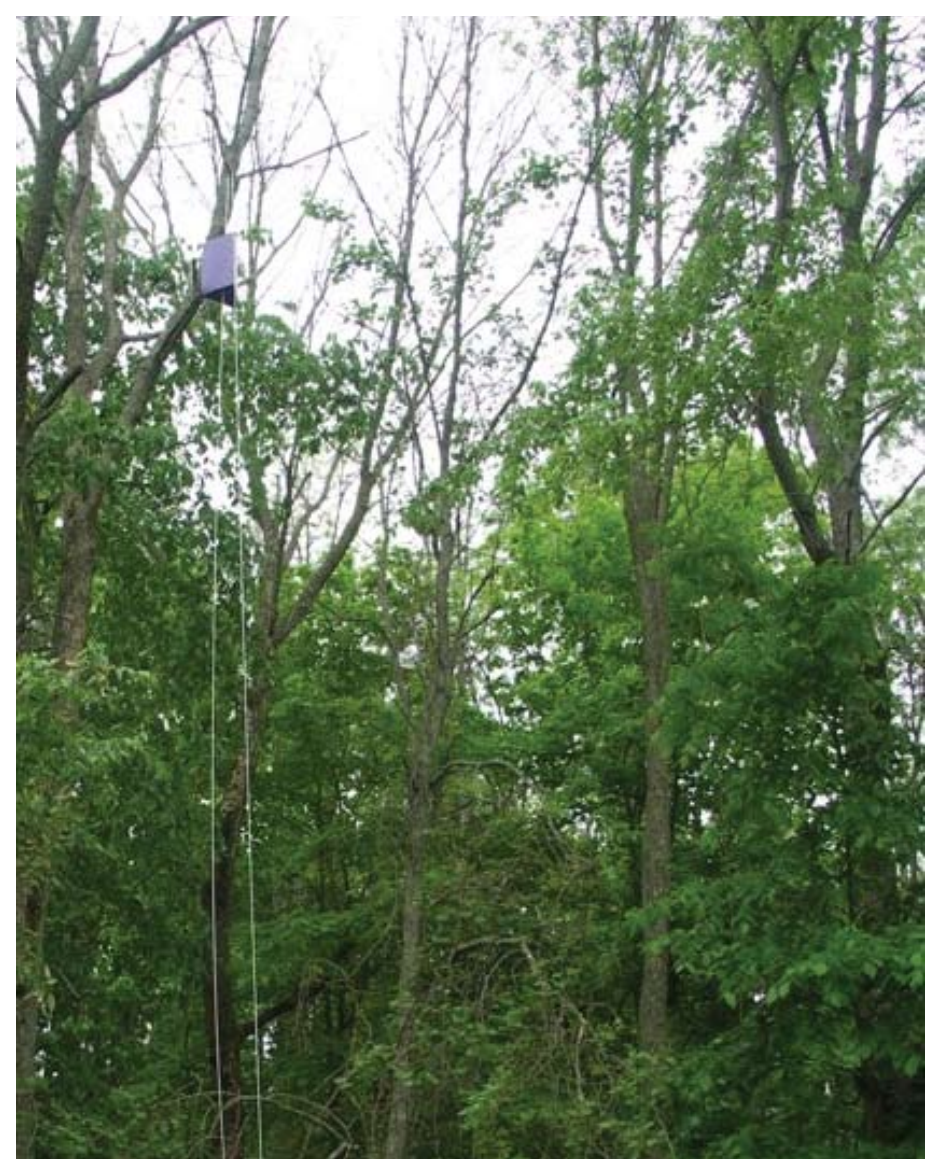

Figure 23-EAB prism traps, deployed at three different heights.

In earlier studies conducted by the Otis Lab staff and researchers from Tennessee State University, more beetles were captured on traps constructed of purple corrugated plastic than on traps of other colors. Recent studies of EAB vision and field behavior in relation to the color and reflectance of ash foliage have led to testing additional colors. In 2007 trials, green traps caught significantly more EABs than traps of other colors did when the green traps were placed in the tree canopy.

In collaboration with researchers from USDA's Forest Service and ARS, CPHST scientists demonstrated that EABs can "smell" a number of chemicals that are emitted by stressed ash trees. Several of these compounds are expensive and difficult to synthesize. But a commercially available oil distilled from the Manuka tree, native to New Zealand, was identified as a possible source. In field studies in Michigan, traps baited with Manuka oil caught more EABs than unbaited traps or traps baited with other lures.

PPQ provided purple prism traps and Manuka oil lures, along with recommendations for hanging them, to State survey pro- 
grams in Illinois, Indiana, Maryland, and New York. Prism traps were also used by researchers with the Otis Lab and the ARS Crop Bioprotection Research Unit and Michigan Technological University in semiochemical lure field assays, color assays, and trapping tool comparisons.

The Otis Lab recommended a Manuka-baited prism trap, and the $\mathrm{EAB}$ program has adopted it for operational use in 2008. CPHST personnel at the Otis Lab will continue to improve trap design and chemical lures for the EAB.

\section{Phytosanitary Risks Associated With Armored Scales in U.S.-Bound Commercial Shipments of Fruit for Consumption \\ Location: Plant Epidemiology and Risk Analysis Laboratory (PERAL), Raleigh, NC}

PPQ requested that the CPHST-PERAL conduct a reevaluation of an existing PPQ policy from 1985 regarding armored scales associated with fresh fruit commodities entering the United States. This request was triggered by a detection of live quarantine pests in imported fruit consignments (fig. 24). Current PPQ policy requires no action when quarantine species of armored scales are intercepted on commercially produced fruit for consumption. However, this policy differs from those of some State-level agencies (e.g., the California Department of Food and Agriculture). PERAL's objective, therefore, was twofold: to determine the likelihood of an introduction into the United States of armored scales entering on fruit for consumption and to justify the existing PPQ policy.

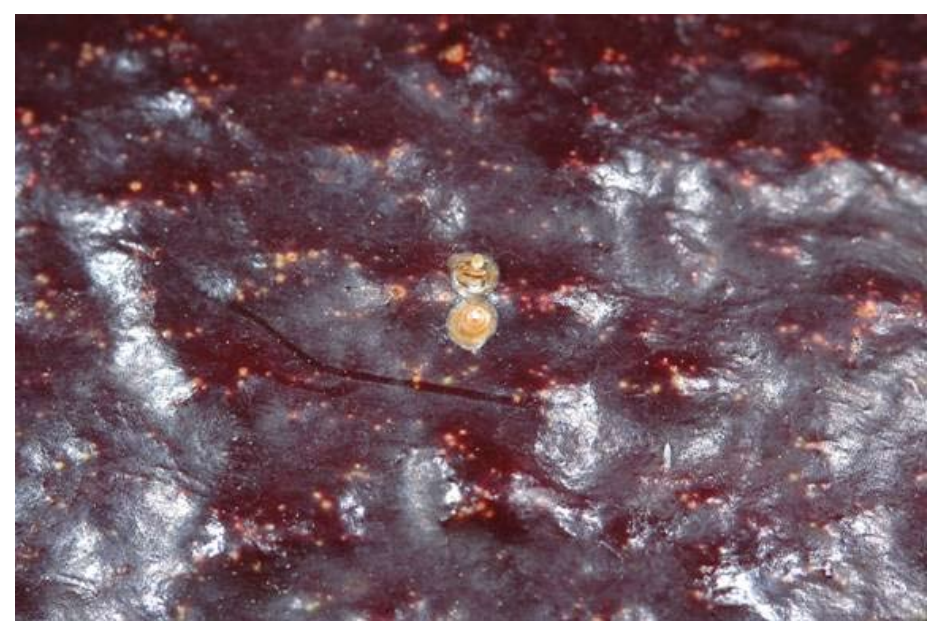

Figure 24-Armored scale detected on avocado. (USDA APHIS photo by PPQ employee Walter Gould.)
The pest risk assessment consisted of gathering evidence from the scientific literature, subject-matter experts, and other relevant sources. PERAL scientists collected information on scale biology and ecology and the potential for dispersal from infested plant material to new hosts in the environment. Finally, PERAL personnel analyzed the pathway factors related to survival and establishment of armored scales.

In general, we assumed that large quantities of commercially produced fruit imported for consumption could be infested with an invasive armored scale species that can reproduce prolifically and without fertilization, can survive on a broad range of host plants in many areas of the United States, and can, potentially, cause serious economic and environmental consequences.

We concluded that the likelihood of an armored scale introduction's entering with commercial fruit is low. In general, armored scales, as a group, have limited natural powers of long-distance dispersal. So they have little ability to come into contact with new hosts if discarded into the environment on infested fruit. They are generally immobile insects with sucking mouth parts that attach to their host (fruit, branches, leaves, etc.) and do not move after initiation of feeding. Commercial fruit shippers remove leaves, stems, and contaminants-the major sites of scale infestation-before their commodities leave the port of origin. In addition, commercially produced fruit has lower pest infestation rates in order to meet industry quality standards. These conclusions were corroborated by the lack of evidence of armored scale establishment in the United States traceable to shipments of commercially produced imported fruit.

\section{Development of Fungal Pathogens as Control Agents for Rangeland Grasshoppers and Mormon Crickets Location: CPHST Lab, Phoenix, AZ}

Rangeland grasshopper and Mormon cricket treatments in federally sponsored control programs rely on insecticide sprays or baits. But such pesticides cannot be used when environmentally sensitive areas are found within proposed treatment zones. Program managers are discovering more and more of these sensitive situations, which complicate (at best) and prevent (at worst) much-needed local or areawide treatments against these range pests. 
Over the last 25 years, scientists and pest-control managers pursued the development of economical, nonchemical treatments for grasshoppers and Mormon crickets. But these efforts have largely proven unsuccessful.

Fungal pathogens could be useful in supplanting toxicants for use in environmentally sensitive places. Three factors make the development of fungal pathogens for use on rangeland pests difficult. First, few candidate U.S. isolates are available. Second, there is no economical system for evaluating candidate pathogens in the field. Third, grasshoppers and Mormon crickets exhibit thermoregulating behavior that interferes with the rapid development of pathogens within the target insects.

Historically, scientists have mainly focused on fungal pathogens for grasshoppers. Recently, however, the focus has shifted to Mormon crickets. These crickets hatch in the spring at

\section{Mormon Cricket Field Mortality}

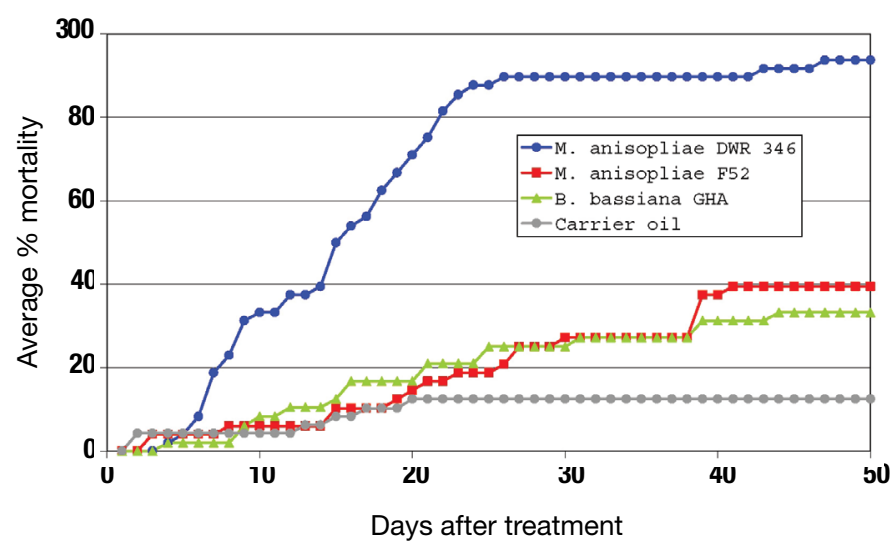

Figure 25-Average mortality of immature Mormon crickets treated with fungal formulations at the CPHST Phoenix Lab.

much lower temperatures than do grasshoppers, thus presenting different temperature parameters for fungal development within the insect. The fungal isolates work better on Mormon crickets hatching in low temperatures than on grasshoppers hatching in higher temperatures (fig. 25).

In 2007, scientists at the Phoenix Lab evaluated a new isolate of Metarbizium anisopliae from Arizona against immature Mormon crickets near Sidney, MT. The investigators compared this isolate, DWR 346, with two historically poor performing isolates (Metarhizium anisopliae F52 and Beauveria bassiana GHA) in field cages. The researchers put cages containing Mormon crickets in place on hundreds of small areas of rangeland and then sprayed these areas with DWR 346. Field Aerial Appli-

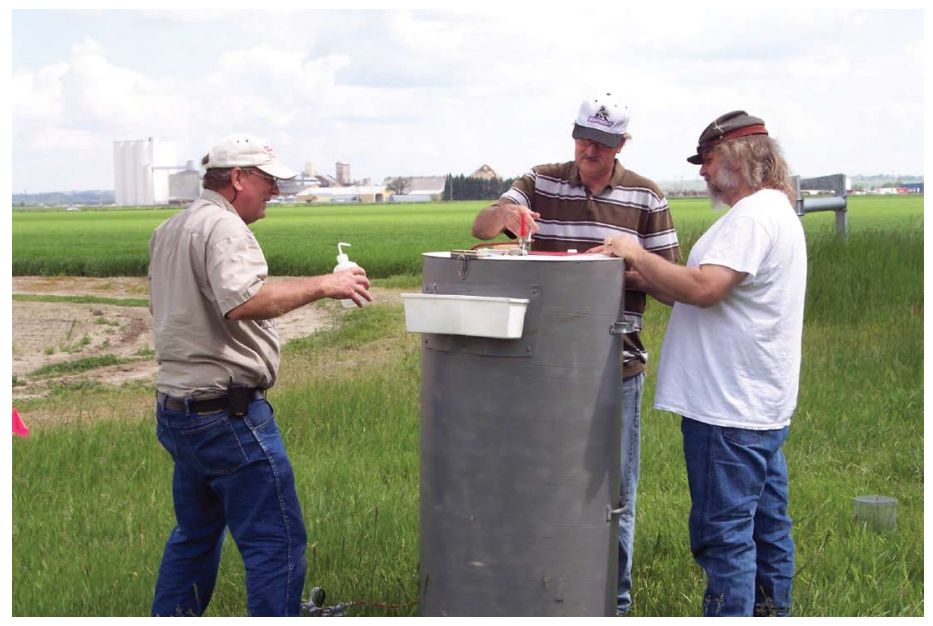

Figure 26-Field Aerial Application Spray Simulation Tower Technology (FAASSTT) used to apply treatments at the Phoenix Lab.

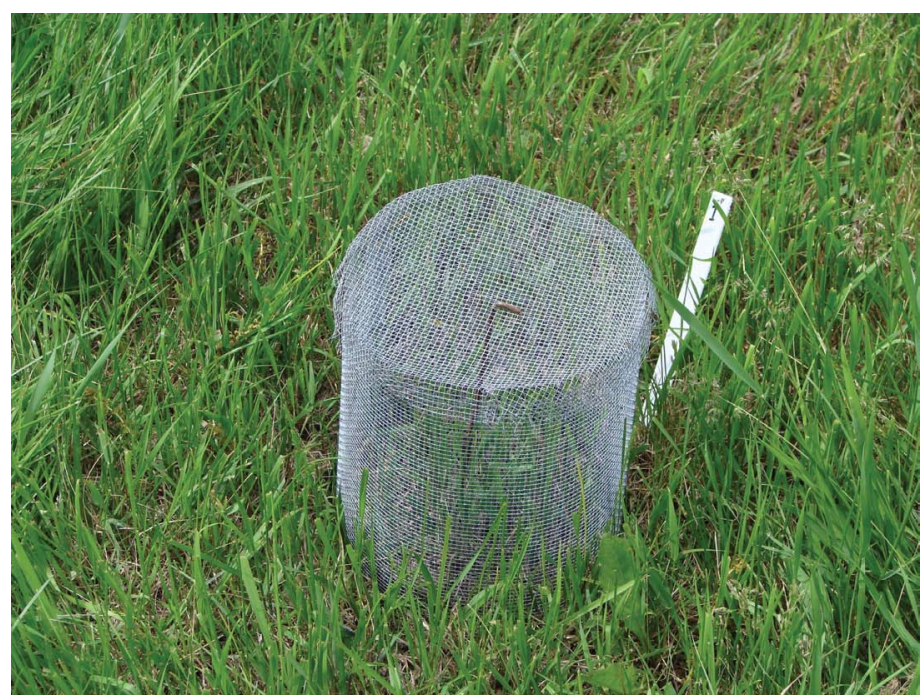

Figure 27-Cage designed at the Phoenix Lab to allow normal insect thermoregulation.

cation Spray Simulation Tower Technology (FAASSTT), which simulates an operational aerial application, was used to spray the isolates (fig. 26). Immature Mormon crickets were confined in cages newly designed to allow normal thermoregulation (fig. 27). Insect surrogates with thermocouples and a recorder were used to estimate cricket temperatures for developing a model to predict when mortality should begin.

DWR 346 demonstrated significant mortality against immature Mormon crickets at 7 days after treatment and produced mortality levels expected of current chemical treatments at about 3 weeks after treatment. This strain appears outstanding compared to other U.S. strains tested to date and offers excellent potential as a realistic nonchemical treatment for Mormon crickets and grasshoppers. 
The development of FAASSTT and the newly designed field cage will greatly facilitate efforts to field-test fungal pathogens. Models being developed from this study will also provide estimates for expected mortality from the use of DWR 346.

The Northern Plains Agricultural Research Laboratory, an ARS facility in Sidney, MT, produces quantities of material for field testing, supplies equipment and technology for modeling insect temperatures to predict onset of mortality, and jointly conducts field and laboratory evaluations with Phoenix Lab personnel. A cooperating scientist from Utah State University discovered and isolated DWR 346 and continues to isolate new strains from soil samples provided by PPQ personnel from North Dakota, South Dakota, and Arizona.

\section{Classical Biological Control of the Emerald Ash Borer \\ Location: Biological Control Unit, Raleigh, NC}

Because the EAB has been in the United States only since the mid-1990s, native natural enemies cause little EAB mortality here. USDA scientists from APHIS, the Forest Service, and ARS conducted foreign exploration for natural enemies that are specific to EAB in China, Mongolia, Japan, Russia, and Korea. These efforts were most successful in China, where $\mathrm{EAB}$ is rare and probably controlled by a combination of host plant resistance and natural enemies. Forest Service cooperators discovered two parasitic wasps in Changchun, China: a small egg parasitoid (Oobius agrili) and a gregarious larval parasitoid (Tetrastichus planipennisi). CPHST scientists from the Otis Lab found another gregarious larval parasitoid (Spathius agrili) in Tianjin, China. This parasitoid has certain characteristics that enhance its usefulness as a biocontrol agent: its life cycle is well synchronized with preferred EAB larval stages, it has several generations per year and a female-biased sex ratio, and it attacks only a narrow range of hosts.

Rearing Spathius presented many challenges. Females attack only larvae of the EAB that are actively feeding inside ash branches. To address this challenge, BCU personnel developed a rearing system in which EAB-sized chambers are drilled in the surface of ash twigs, larvae are inserted into the grooves, and the sticks are wrapped with floral tape through which the Spathius will oviposit.
A second challenge in rearing Spathius parasitoids is the limitation that EAB larval feeding patterns impose. Because the pests quit feeding in the winter, continuous production of the parasitoid is curtailed. We solved this problem by cutting and storing logs infested with mature larvae in a cold room.

In order to gain permission to release the parasitoid from quarantine, we initiated tests to determine whether Spathius would attack native wood-boring species. Host specificity testing in

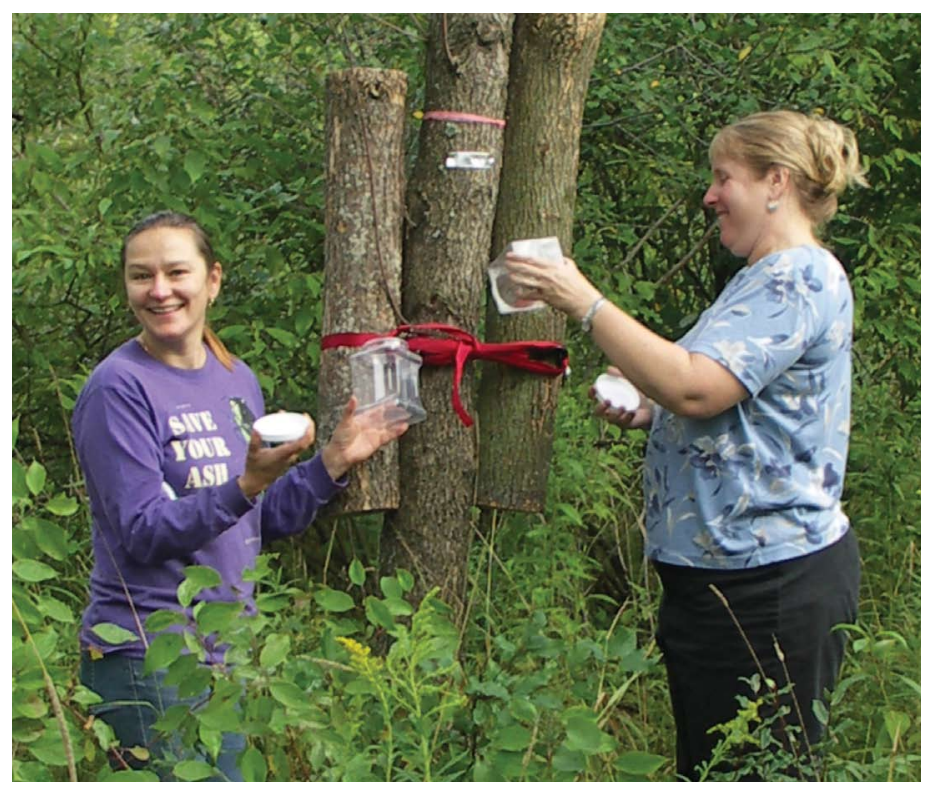

Figure 28-lvich and Juli releasing Spathius in August 2007. (USDA APHIS photo by CPHST Otis Lab.)

the United States and China indicated that, in no-choice tests, Spathius would lay some eggs on other Agrilus species, but attack rates were significantly lower than on EABs. Olfactometer tests showed that Spathius is attracted to leaves of ash, willow, and Chinese prickly ash only and not to 10 other trees tested. In addition, a collection in China of more than 2,000 larvae from 6 Agrilus species produced many species of parasitic wasps, but no Spathius agrili (fig. 28).

In January 2007, we submitted our research results along with an application for a permit to release Spathius parasitoids in the field. Following publication of an Environmental Assessment and a 60-day period of public comment, release permits were issued, and Spathius was released in August and September. BCU investigators are planning future studies to evaluate establishment, dispersal, and impact of Spathius parasitoids on $\mathrm{EABs}$ and select nontarget wood borers. 
Development and Implementation of Organizational and Technical Infrastructure To Support Use of Irradiation as a Phytosanitary Treatment Location: Treatment Quality Assurance Unit (TQAU), Raleigh, NC

Irradiation is an effective phytosanitary treatment that uses ionizing radiation to achieve one of five endpoints: pest inability to emerge or fly, mortality, sterility, inactivation, or devitalization. This technology could serve as a valuable pest-mitigation tool and, for fresh fruits and vegetables, may replace or reduce other treatments that damage the environment or negatively affect fruit quality. Interest in irradiation has increased substantially over the years, and APHIS identified the need to develop a framework to implement an irradiation treatment program on a global scale.

In 2007, the agency initiated a project to establish an irradiation treatment program. Allowing irradiation as a pestmitigation option required developing regulatory protocols, treatment dosages, certification standards, treatment tracking, and reporting procedures. The TQAU was instrumental in this endeavor, working closely with various agency program units, including PPQ Quarantine Policy Analysis and Support (QPAS), Phytosanitary Issues Management (PIM), and Commodity Imports Analyses and Operations (CIAO), and APHIS-International Services and USDA's ARS. TQAU also consulted with multiple industry representatives and organizations like ASTM International [formerly known as the American Society for Testing and Materials], the irradiation industry, the U.S. Department of Commerce's National Institute of Standards and Technology, and the International Atomic Energy Agency.

The capstone accomplishment of the program was the April 2007 certification of the KRUSHAK irradiation facility for treatment of mangoes in Lasalgaon, India. TQAU guided much of the policy development by providing and validating treatment data, including the use of generic doses based on pests of concern. TQAU staff also served as scientific advisers in development of the generic operational workplan (OWP) that regulates use of irradiation in preclearance programs. To support the OWP, TQAU staff attended bilateral trade meetings in India and Mexico and provided technical expertise to QPAS and PIM staff. TQAU cohosted an irradiation training workshop in January 2007 that was attended by a range of APHIS, industry, and international personnel. Shortly after this workshop, new chapters in the PPQ Treatment Manual outlining certification standards and irradiation treatments were completed. TQAU also began work on the Irradiation Reporting and Accountability Database, an online tool that tracks details and traceback information for irradiation treatments. These milestones laid the foundation for the irradiation program, allowing for the successful certification of KRUSHAK, the first cobalt-60 gamma irradiation facility in the world to be certified by APHIS for phytosanitary treatment.

The use of irradiation will open channels for the importation of many commodities that currently lack treatment options. The popularity of irradiation as a phytosanitary treatment continues to increase. The infrastructure developed in the past year by TQAU was fundamental in launching the agency's irradiation program. Internal customers (PPQ and International Services) and external stakeholders (industry and foreign governments) will continue to utilize the policies and technology developed by TQAU. 



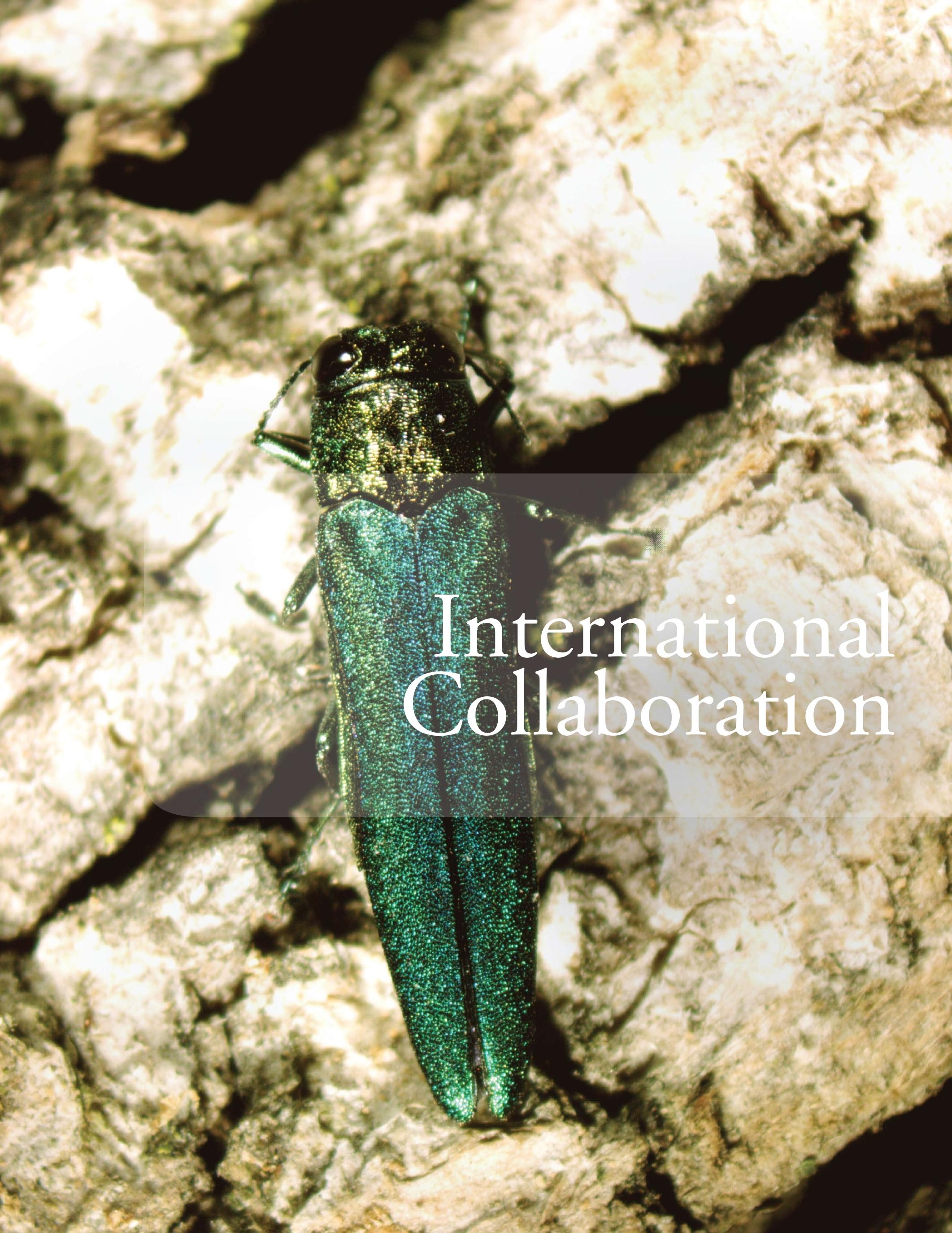




\section{Safeguarding Our Borders}

International partners and collaborators provide support to the safeguarding of our borders from invasive plant pests and pathogens. In 2007 CPHST worked in 35 countries on national and global projects (fig. 29).

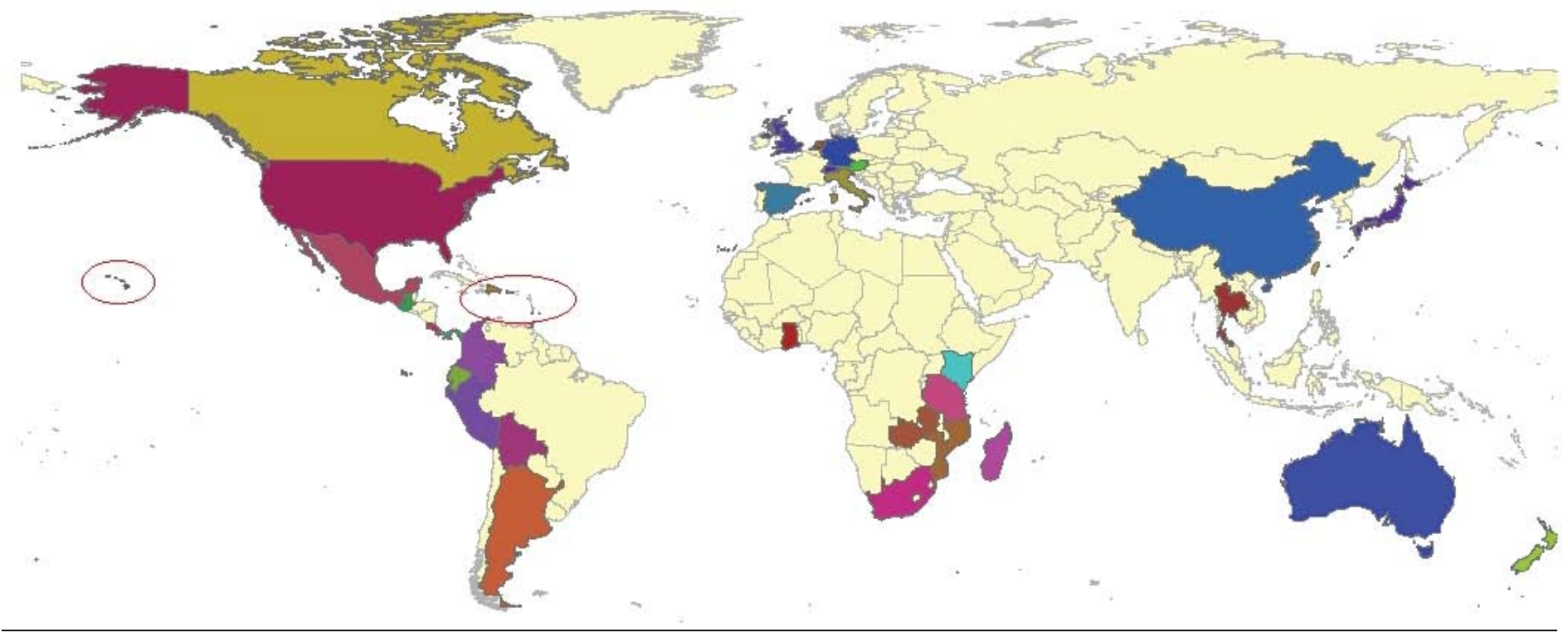

Figure 29-Map of countries where CPHST worked in 2007. (Map developed by CPHST PERAL staff.)

Argentina

Australia

Austria

Barbados

Bolivia

Canada

Cayman Islands

China

Colombia

Costa Rica

Dominican Republic

Ecuador

Germany
Ghana
Guatemala
Italy
Japan
Kenya
Madagascar
Mexico
Mozambique
Netherlands
New Zealand
Panama
Peru

Germany

Guatemala

Italy

Japan

Kenya

Madagascar

Mozambique

Netherlands

Panama

Peru
Saint Lucia

South Africa

Spain

St. Vincent and the Grenadines

Switzerland

Taiwan

Tanzania

Thailand

Trinidad

United Kingdom

United States (including Puerto

Rico and Hawaii)

Zambia 


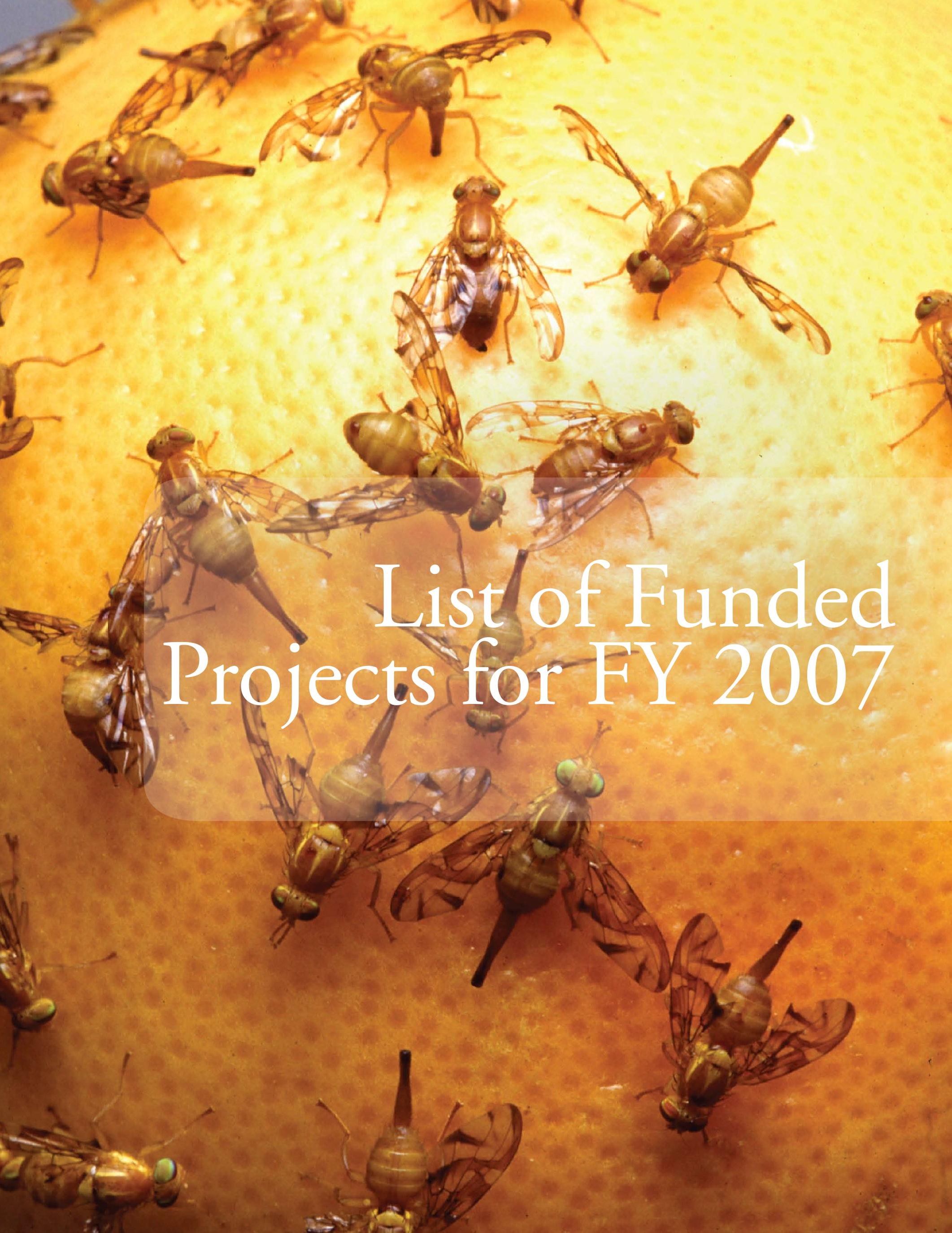




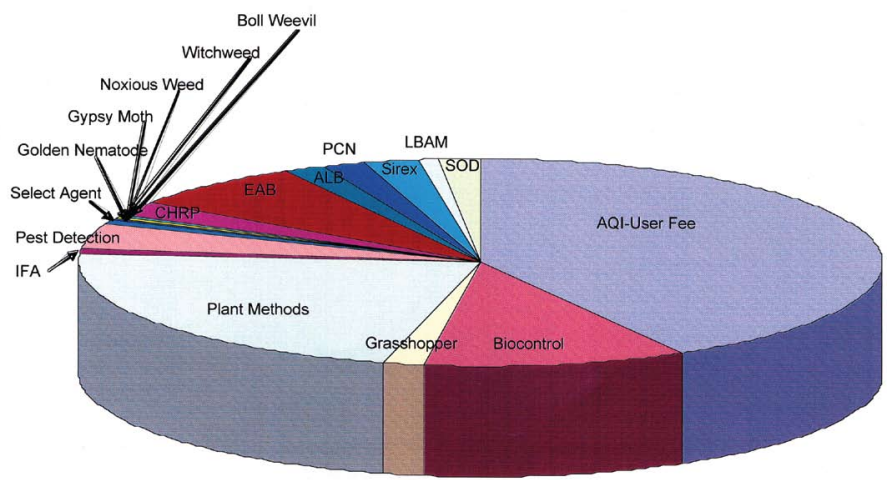

$\begin{array}{lll}\text { AQI-User Fee } & \square \text { Select Agent } & \square \text { EAB } \\ \text { Biocontrol } & \square \text { Golden Nematode } & \square \text { ALB } \\ \text { Grasshopper } & \square \text { Gypsy Moth } & \square \text { PCN } \\ \text { Plant Methods } & \square \text { Noxious Weed } & \square \text { Sirex } \\ \text { IFA } & \text { Witchweed } & \square \text { LBAM } \\ \text { Pest Detection } & \square \text { Boll Weevil } & \square \text { SOD } \\ & \square \text { CHRP } & \end{array}$

Figure 30—CPHST funds projects based on APHIS priorities.

Figure 30 shows a breakdown of how funding was allocated across all CPHST units in FY 2007.

\section{Beltsville Lab}

\section{Plant Pathogen Methods Development}

- Develop a real-time PCR for the detection of the citrus variegated chlorosis strain of Xylella fastidiosa

- Develop group-specific nucleic acid-based diagnostic assays for the improved detection of geminiviruses and potyviruses infecting imported germplasm

- Develop sampling methods for improved detection and identification of the causal bacterium of citrus greening [huanglongbing]

- Develop advanced PPV diagnostics

- Develop DNA chip for rapid detection of regulated plant pathogens

\section{Validation of Plant Pathogen Diagnostic Methods}

- Validate the ARS-developed PCR detection method for PCN

- Validate PCR diagnostics methods for Phytophthora kernoviae

\section{Fort Collins Lab}

Control of Invasive Weeds

- Develop rearing systems for beneficial root feeders

- Develop biocontrol integrated pest management (IPM) for Canada thistle

- Develop biocontrol methods to manage

-Russian knapweed

—Field bindweed

— Garlic mustard and toadflax

- Hoary cress

- Hound's tongue

- Saltcedar (Tamarisk)

- Cogongrass weed

-Orange hawkweed (Hieracium aurantiacum)

- Conduct surveys for natural enemies of

- Perennial pepperweed

—Canada thistle

- Control common tansy

- Control Dyer's woad/perennial pepperweed

- Explore biocontrol prospects for musk thistle and Scotch thistle

- Discover an egg parasitoid for cereal leaf beetle

- Explore the possibility of reducing Benghal dayflower seedbank populations with soil-active herbicides or sunn hemp and ryegrass cover crops

- Develop databases to calculate localized spread rates for three invasive weeds, using GPS/GIS technology to measure spatial and temporal patterns for monotypic or patchy infestations

- Devise an efficacy screening study for synthetic and organic herbicides on giant hogweed resprouts, applied as injection or foliar sprays

- Create a herbicide screening field study for onionwed

\section{CAPS Science Support}

- Develop CAPS Commodity-based Survey Reference and Guidelines documents

- Prioritize pests for the CAPS program

\section{Pest Identification Technology}

- Develop invasive insect screening tool

- Develop Lucid ID resources for target pests 


\section{Spatial Technologies}

- Refine GIS and spatial analysis for grasshoppers

- Carry out saltcedar (Tamarisk) GIS project

- Conduct dalmatian toadflax GIS analysis

\section{Gulfport Lab}

\section{Biocontrol and Quarantine Treatments for} Soil-Inhabiting Pests

- With regard to the IFA:

- Conduct biological control using phorid flies

- Develop new bait treatments for control

- Evaluate methods to prevent IFAs from infesting baled hay and pine straw

- Develop IFA quarantine treatments for field-grown and balled-and-burlapped nursery stock

- Initiate a cooperative project with ARS for areawide suppression of IFA populations in pastures

- Evaluate methods to prevent IFAs from infesting commercial honey-bee pollination operations

- Monitor field releases of Thelohania solenopsae and Pseudacteon spp. as biocontrol agents

- Create a GIS decision-support and management program for evaluation of beneficial exotic anthropods (e.g., phorid flies)

- Carry out R\&D Need No. I-39

- Develop new treatments for containerized nursery stock (e.g., incorporation, drench, nontraditional methods)

\section{Chemistry Section-Environmental Monitoring and Analysis}

- Assist with commodity and pest source identification

\section{Mission Lab}

\section{Fruit-Fly Programs Support and Methods Development}

- Evaluate augmentative release of braconid parasitoids

- Research and development support for field program activities

- Provide support for PRP and eradication

- With regard to fruit flies:

- Evaluate candidate baits and trap types

- Evaluate fruit-fly lures and attractants (Sentry CRADA)
- Enhance the performance of male oriental fruit flies in the SIT

- Manipulate the adult diet of sterile Mediterranean fruit flies (Medflies) in SIT

- Mass-produce sterile insects and operational quarantine facilities

- Release natural enemies of the West Indian fruit fly in Puerto Rico

- Evaluate genetically modified strains of Medfly

- Refine diet formulations for the Mexican fruit fly (MFF), solve production problems, and develop new mass-production systems

- Develop new MFF strains for mass-rearing

- Assess toxins in a bait as an alternate method to sup press MFF

- Evaluate preservatives to enhance identification of Anastrepha spp. and Ceratitis capitata adults

- Implement the incubation of MFF eggs by bubbling into the MFF rearing facility

- Identify and suppress microbials

- Develop methyl bromide protocol

- Genetically modified organisms (GMO) of Mexican fruit fly

- Baits with thickeners and adhesives and nonprotein attractants for use in bait stations and other delivery methods

\section{Development of Molecular Diagnostics for Arthropods and Invertebrates}

- Develop and implement rapid molecular identification technology for insects, with major focus on immature fruit flies

- Develop molecular diagnostic techniques that identify foreign sources of fruit-fly pest introductions

- Develop molecular techniques that identify cryptic thrip species

- Develop a molecular diagnostic tool for the genus Anastrepha (Tephritidae)

- Develop molecular diagnostic techniques for mollusks of economic importance to American agriculture

- Develop diagnostic tools for identifying species and geographic sources of intercepted dacine fruit flies (Tephritidae: Dacinae)

- Continue operation of the CPHST arthropod quarantine facility 


\section{Biological Control and Integrated Pest}

\section{Management}

- Develop control methods for giant African snail

- Conduct tropical soda apple project

- Evaluate the biological control of ACP in the Rio Grande Valley of Texas

- Conduct Asian cycad scale project

- Develop effective minimum trapping standards for boll weevils following eradication

\section{Development and Applications of Spatial} Technology for Pest Detection and Assessment

- Apply remote sensing technology for detection of EABinfested trees

\section{Detection and Management of Citrus Pests and Diseases}

- Survey for, detect, and manage significant agricultural pests in the greater Caribbean Basin

- Conduct sentinel tree monitoring for citrus canker in Texas

- Carry out citrus canker epidemiology studies

\section{Otis Lab}

\section{Forest Pests Program Support and Methods Development}

- Conduct gypsy moth nuclear polyhedrosis virus production

- Carry out gypsy moth risk mapping for uninfested portions of the United States

- Conduct gypsy moth searching and mating

- Provide support for the Russian Far Eastern Exotic Lymantriidae Exclusion Program and develop and support monitoring systems for targeted exotic species

- Forecast pest potential through offshore assessments

- Conduct molecular analysis of male gypsy moths trapped at U.S. ports and other high-risk sites

\section{ALB}

- Evaluate insecticides in China for the control of the ALB and other Anoplophora species

- Improve rearing technology for the ALB

- Investigate infestation dynamics of the ALB in North America
- Evaluate the ALB's preference of tree species and their suitability for survey and prophylactic treatments

- Accelerate methods development for control of exotic wood borers

- Application of systemic pesticides and treatment support for the ALB eradication program

- Perform molecular and genetic analyses of Anoplophora species

EAB

- Develop methods for control of exotic wood borers

- Pesticide residue determination and assay development

- Develop survey tools and alternative control strategies for the $\mathrm{EAB}$

- Conduct studies on EAB ecology: adult movement and biological control by natural enemies

- Evaluate systemic insecticides in China for the control of the $\mathrm{EAB}$

- Investigate the distribution of EAB and its host trees in China

- Assess fumigation with sulfuryl fluoride as a quarantine treatment for $\mathrm{EAB}$ in merchantable logs and timber

- Develop dry heat, chipping, mulching, and microwave applications for use as EAB quarantine treatments

- Develop EAB attractants

- Carry out trap design studies

\section{Sirex Wood Wasps}

- Develop monitoring tools for Sirex noctilio

- Implement and evaluate biological control of S. noctilio

- Develop diet and rearing methods for Sirex in quarantine

- Validate treatment options for wood commodities infested with $S$. noctilio

- Develop a degree-day model for $S$. noctilio

- Evaluate the infestation dynamics of $S$. noctilio in North America as applied to survey and management problems 


\section{Biological Control and Integrated Pest}

\section{Management}

- Enhance production of insect diets and life stages for use in APHIS and other cooperative research programs

\section{AQI and Commodity-Treatment Program Support and Methods Development}

- Investigate nonchemical metabolic stress disinfestation using radiofrequency as a potential mitigation and quarantine method and alternative to methyl bromide fumigation

- Develop alternative quarantine treatments for invasive hitchhiking snails

- Assess the efficacy of alternative fumigants to control solid wood packing pathogens, including Phytophthora ramorum

- Evaluate fumigation with methyl bromide and sulfuryl fluoride as a quarantine treatment for control of woodboring insects

- Integrate molecular diagnostics and pest risk assessments for improved detection and identification of Copitarsia decolora (Noctuidae)

- Assess the use of gamma radiation and phosphine gas in combination with sustained cold treatment as a methyl bromide alternative for treating imported fruits

- Determine the effect of heat treatment to control Phytophthora ramorum-infected wood

- Determine commodity treatments for bamboo

- Pest Survey and Detection Program Support

- Evaluate odor-based detection and monitoring systems for exotic pests

- Survey, detection, and treatment evaluation on insects associated with wood packaging materials from China

\section{Other Projects}

- Evaluate the application of remote sensing technology to the survey and detection of exotic invasive plant pests

- Develop methods for managing or eradicating Catoblastis cactorum in North America

\section{Phoenix Lab}

Rangeland Grasshopper and Mormon Cricket Monitoring and Control

- Develop a mycoacridacide, a mycoinsecticide, and a bacteria-derived toxin as biorational control options for grasshoppers and Mormon crickets on rangeland

- Develop, evaluate, demonstrate, and implement improved formulations and biorational use of malathion for controlling grasshoppers on rangeland

- Develop data to improve and standardize carbaryl bait use against Mormon crickets

\section{Pink Bollworm (PBW) Eradication Methods Development}

- Improve mass-rearing and sterile-insect quality-control methods and development, including testing lower doses of irradiation

- Evaluate methods and development of advanced genetic control and sterile insect technology for improvement to PBW eradications and suppression programs project

- Continue PBW eradication methods development

\section{Plant Epidemiology and Risk Analysis} Laboratory New Pest Advisory Group (NPAG)

- New Pest Advisory Group (NPAG)

NAPPFAST (Risk Mapping) and Scientific Information and Phytosanitary Analysis

- NAPPFAST

Quarantine 56 and Quarantine 37 (Commodity PRAs )

- Initiate a Q-56 risk assessments project

- CIPM Agreement

Weed PRAs

- PERAL Weed Team 
IPPC/NAPPO (international standards)

- Establish IPPC and NAPPO Standards Working Groups

Other PERAL Projects

- Global Pest and Disease Database

- AQIM-QA

- Library

- Regulatory curriculum (North Carolina State University)

- CAPS pest prioritization

\section{Biological Control Unit}

Offshore Safeguarding: Biological Control and Other Strategies To Detect and Mitigate Invasive Pests

- Canal zone sentinel survey

- Offshore mitigation of invasive pests

Domestic Safeguarding: Biological Control and Other Strategies To Detect and Mitigate Invasive Pests

- Field release and evaluation of natural enemies for tropical soda apple

\section{Treatment Quality Assurance Unit} Commodity Treatment Information Systems (CTIS)

- CTIS agreement and updates for online 429 application

\section{Director's Office}

\section{Other Projects}

- Develop pest diagnostics and information management

- CPHST director of plant medicine agreement 
Notes 
